\title{
WestVirginiaUniversity
}

THE RESEARCH REPOSITORY @ WVU

Graduate Theses, Dissertations, and Problem Reports

2002

\section{Predictors of student success in distance education courses}

Rhonda Suzanne Shepperd

West Virginia University

Follow this and additional works at: https://researchrepository.wvu.edu/etd

\section{Recommended Citation}

Shepperd, Rhonda Suzanne, "Predictors of student success in distance education courses" (2002).

Graduate Theses, Dissertations, and Problem Reports. 2471.

https://researchrepository.wvu.edu/etd/2471

This Dissertation is protected by copyright and/or related rights. It has been brought to you by the The Research Repository @ WVU with permission from the rights-holder(s). You are free to use this Dissertation in any way that is permitted by the copyright and related rights legislation that applies to your use. For other uses you must obtain permission from the rights-holder(s) directly, unless additional rights are indicated by a Creative Commons license in the record and/ or on the work itself. This Dissertation has been accepted for inclusion in WVU Graduate Theses, Dissertations, and Problem Reports collection by an authorized administrator of The Research Repository @ WVU.

For more information, please contact researchrepository@mail.wvu.edu. 
Predictors of Student Success in Distance Education Courses

Rhonda Suzanne Shepperd

Dissertation submitted to the College of Human Resources and Education at West Virginia University in partial fulfillment of the requirements for the degree of

Doctor of Education

in

Educational Leadership

Teresa Eagle, Ed.D., Chair

Ernest Goeres, Ph.D.

Patsy Haslam, Ed.D.

Rudy Pauley, Ed.D.

Jack Yeager, Ed.D.

Department of Educational Leadership

Morgantown, West Virginia

2002

Keywords: Student Success, Distance Education, Attrition, Communication, Time Management, Expectations, Quality of Instruction, Procrastination, Predictors 


\section{ABSTRACT \\ Predictors of Student Success in Distance Education Courses \\ Rhonda Suzanne Shepperd}

This study investigated the relationship between faculty-student communication, student time management, student expectations, and quality of instruction and the level of student success in distance courses. The population of the study consisted of undergraduate students enrolled in Independent Study courses at Mountain State University ( $N=1007)$ during the summer and fall 2001 terms. The sample consisted of 500 students randomly selected from the population. Participants completed the Distance Education Satisfaction Survey developed by the researcher. Data analyses indicated that statistically significant differences existed within faculty-student communication, student time management, student expectations and quality of instruction based on the level of student success. Ancillary findings indicated that statistically significant differences existed within the turnaround time for grades, time management skills, ability to balance multiple roles, pacing ability, beginning course early, amount of work, self-directed nature, quality of work, course quality, and instructor support and guidance based upon the level of student success. 


\section{DEDICATION}

This work is dedicated with love to my husband, Jack, and my daughter,

Rachel. Without their unconditional love and support, this document would have not been possible. 


\section{ACKNOWLEDGEMENTS}

I would like to express my deepest gratitude to several people who have greatly impacted my journey through this program and most importantly, the completion of the dissertation phase.

- My committee members, Dr. Teresa Eagle, Dr. Rudy Pauley, Dr. Jack Yeager, Dr. Ernest Goeres, and Dr. Patsy Haslam, each committee member has contributed to my success throughout this program in very special and unique ways.

- My Minor Chair, Dr. Pauley, who directed my dissertation with great finesse, support and motivation throughout the process. I appreciate everything.

- My great friend, Dr. Jim Hodge, who shared the successes and frustrations over the last $3 \frac{1}{2}$ years, not to mention he made the thousands of miles we traveled on the West Virginia Turnpike more pleasant and fun. You have been, and continue to be, a fabulous colleague and supportive friend.

- My Mom and Dad, Mr. and Mrs. Norman Blankenship, who have instilled in me that an education is very important and serves as the key to your successes and dreams. You have been, and continue to be, my role models in all that I do.

- My husband, Jack, thank you for sharing my ups and downs in the program with understanding and compassion and being there when I needed you.

- My daughter, Rachel, thank you for being the sunshine in my life each day. Your hugs and kisses have helped me more than you will ever know. You are my sunshine and bring such love, excitement, and meaning to my life. 


\section{TABLE OF CONTENTS}

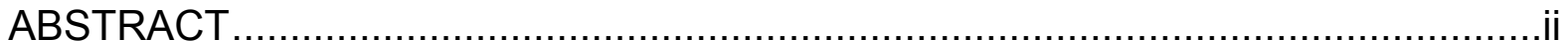

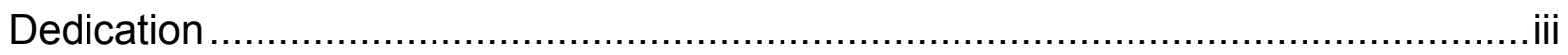

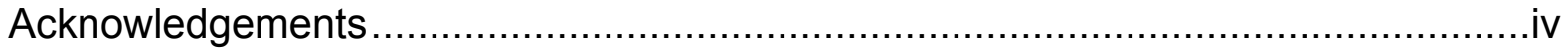

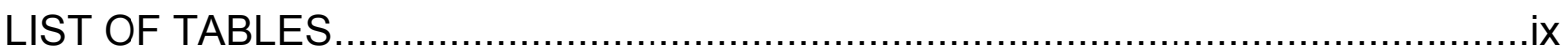

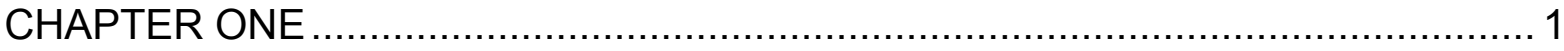

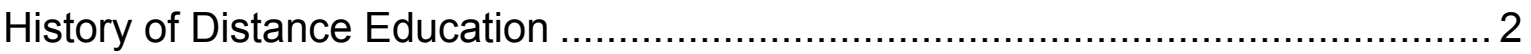

Growth in Distance Education Programs ..................................................... 2

Distance Education Purpose and Characteristics ......................................... 4

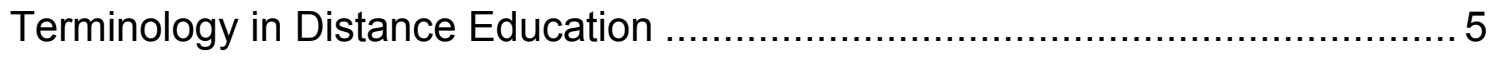

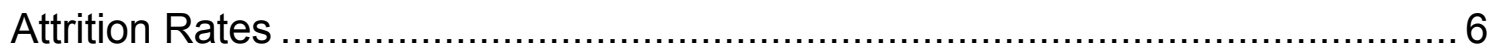

Student Success in Distance Education ...................................................... 7

Impact of Distance Education on College and University Administrators .............. 9

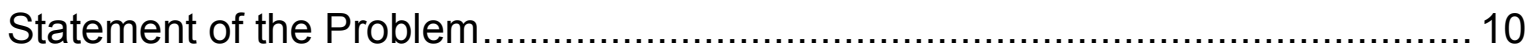

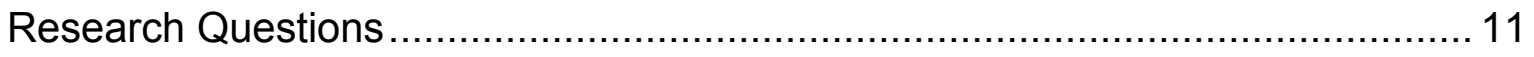

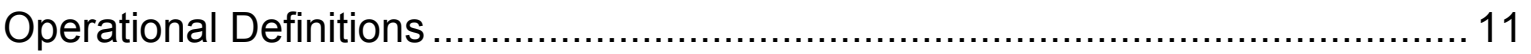

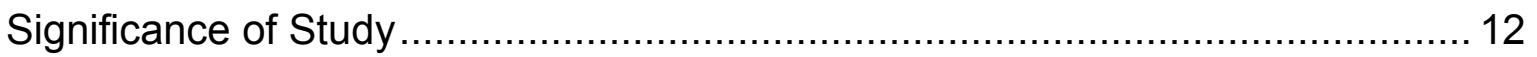

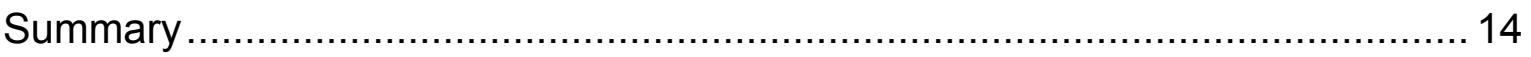

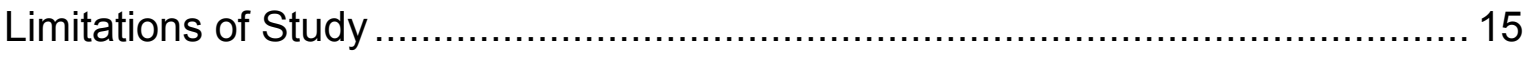

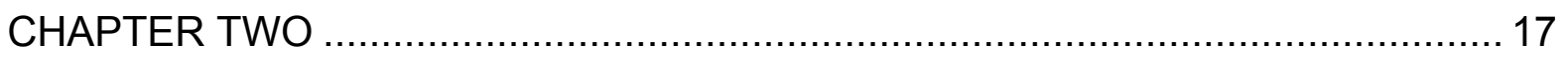

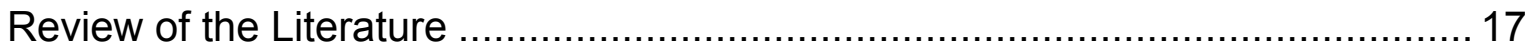

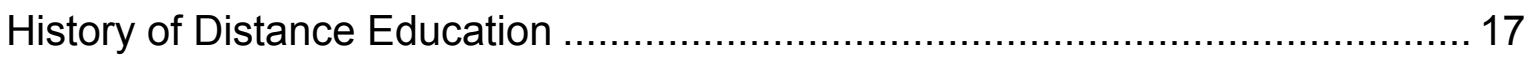

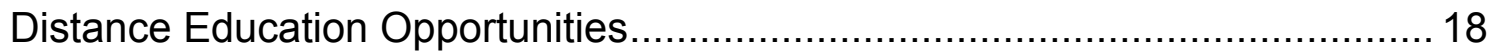


Distance Education Purpose and Characteristics ......................................... 19

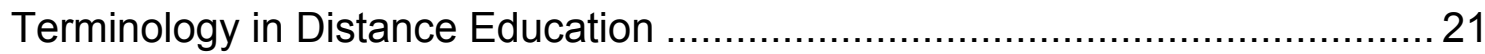

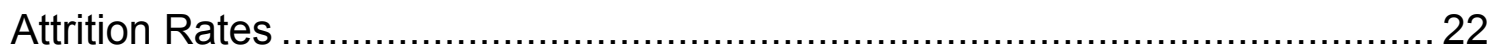

Student Success in Distance Education ..................................................... 23

Faculty-Student Communication ......................................................... 24

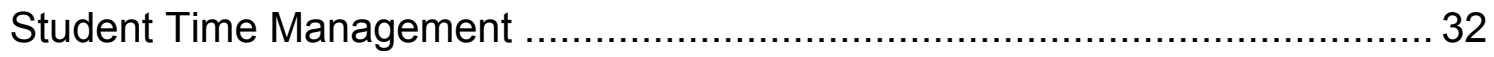

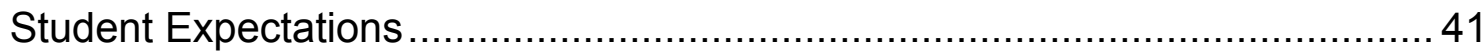

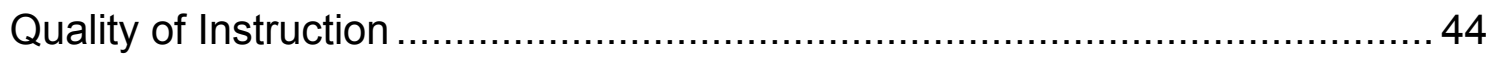

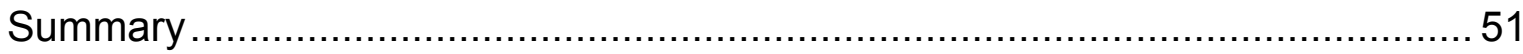

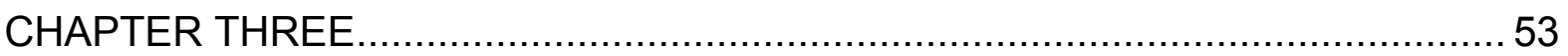

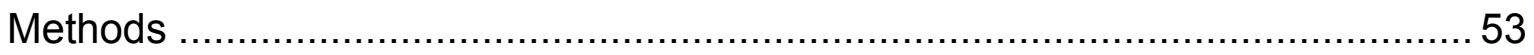

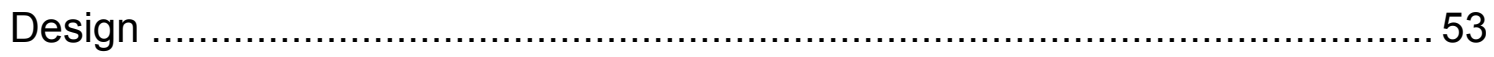

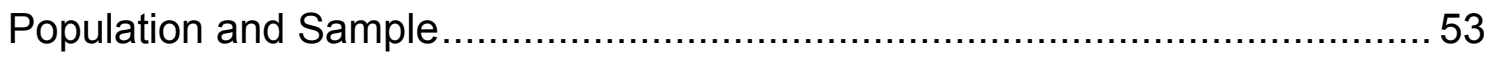

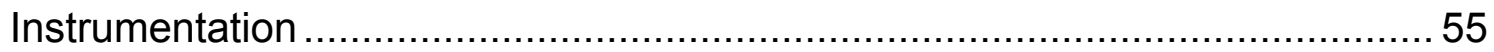

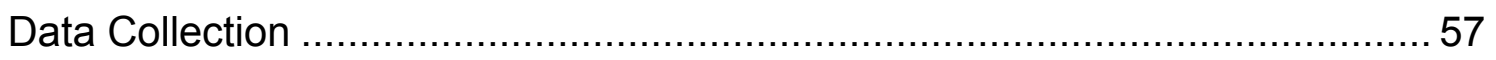

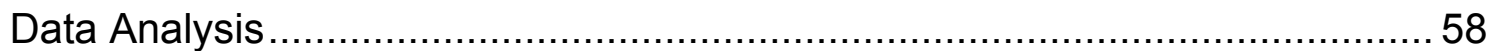

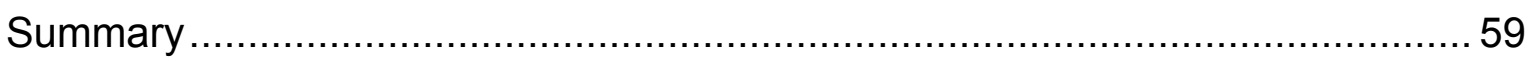

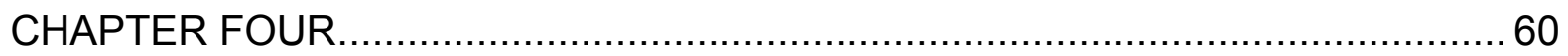

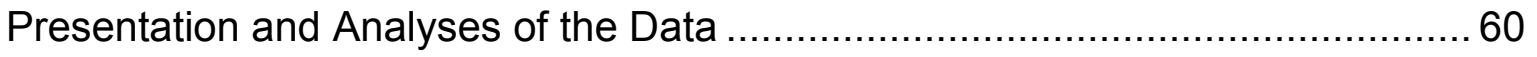

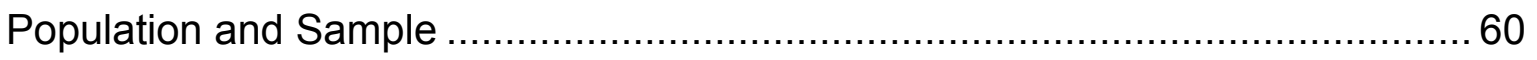

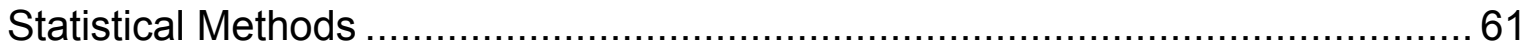

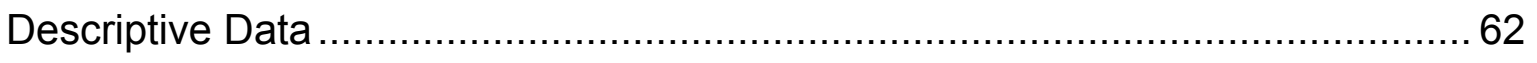

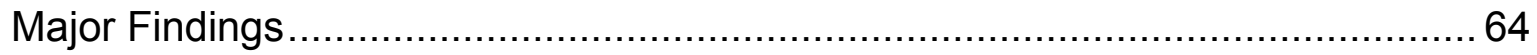




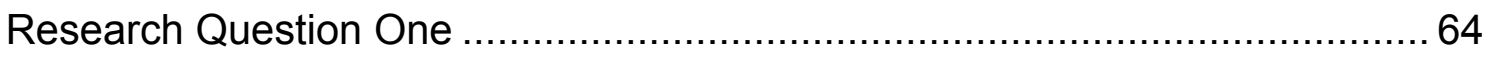

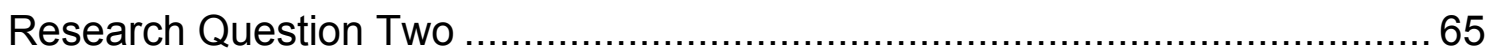

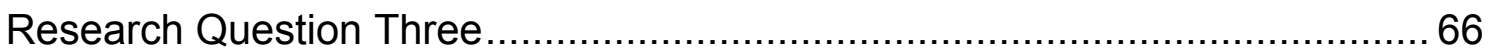

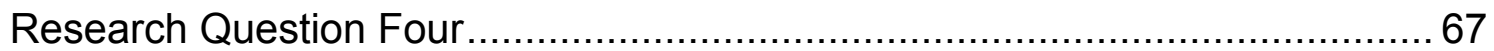

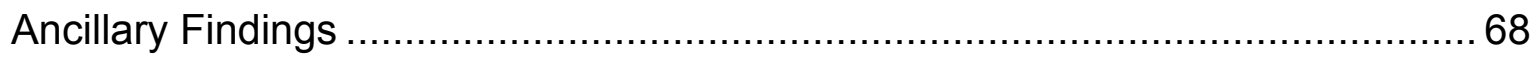

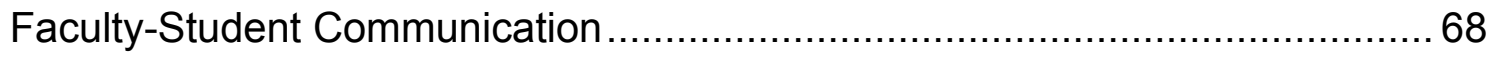

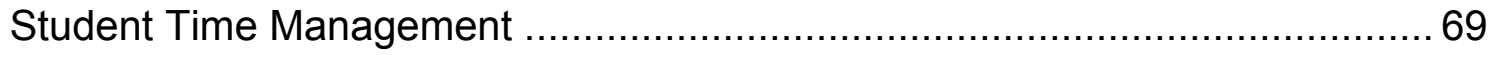

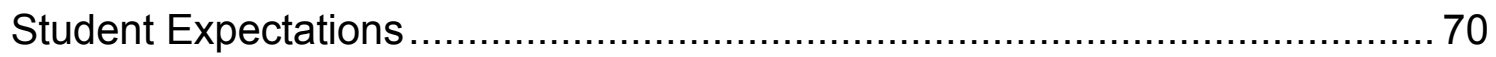

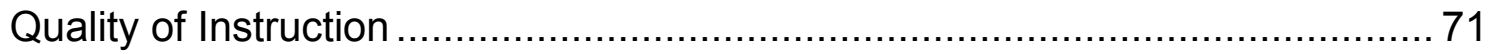

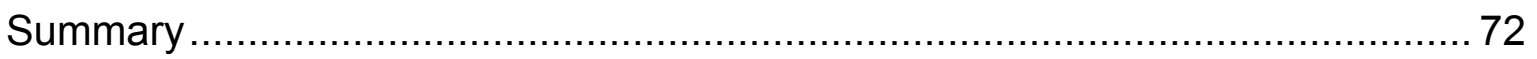

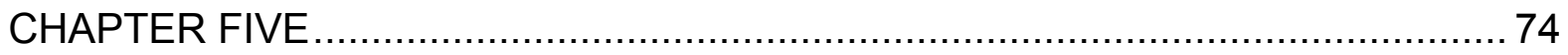

Summary, Conclusions, and Recommendations.......................................... 74

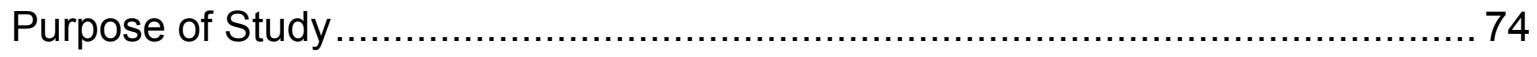

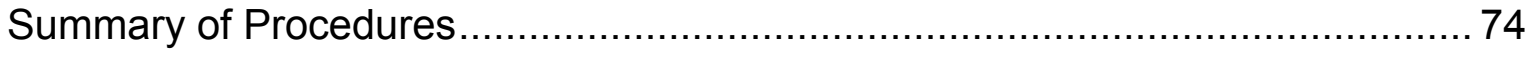

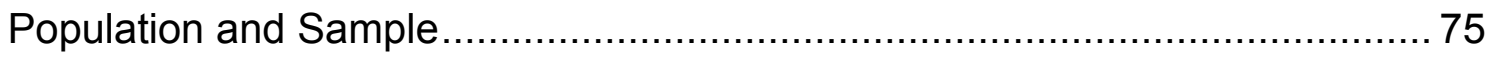

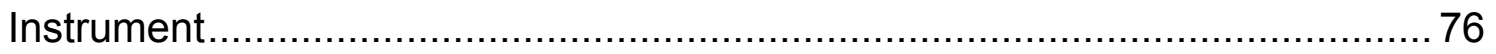

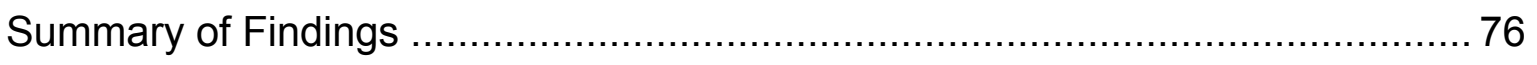

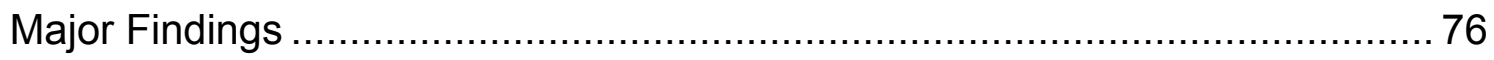

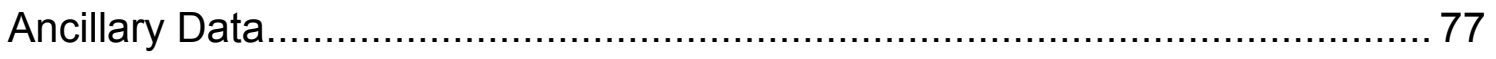

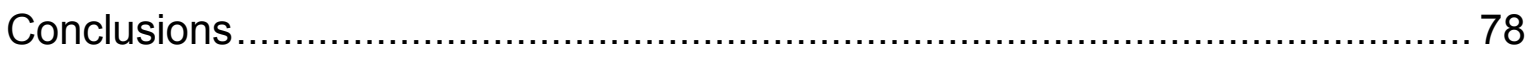

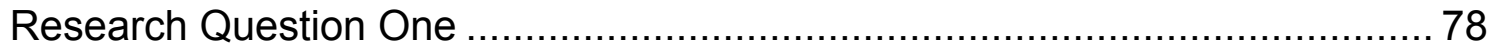

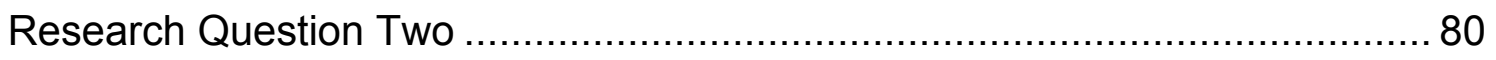

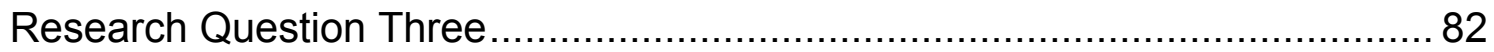




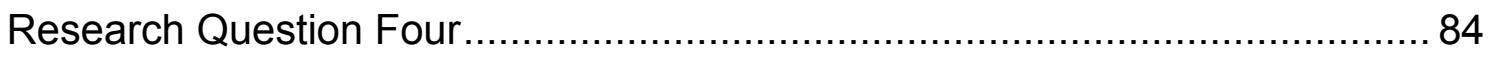

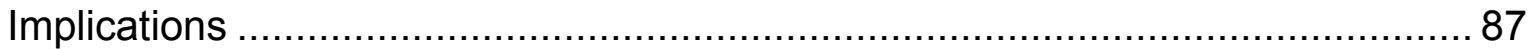

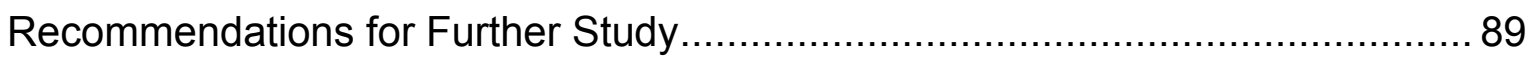

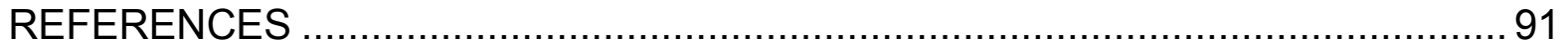

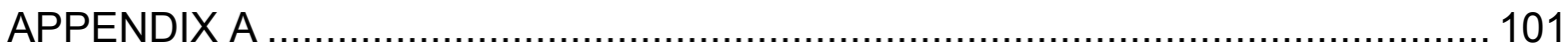

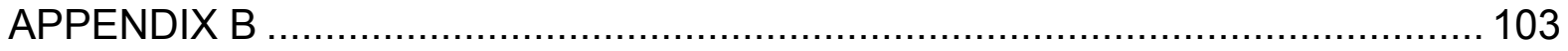

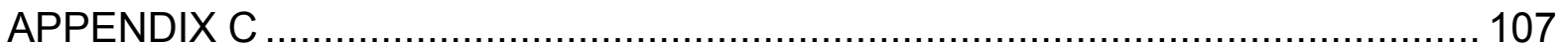

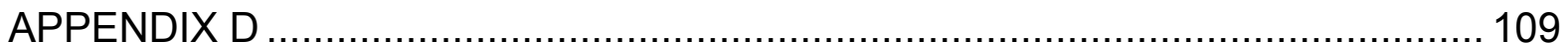




\section{LIST OF TABLES}

Frequency of Level of Student Success.

Summary of One-Way Analysis of Variance for Faculty-Student Communication

(Survey Questions 1-4) 65

Summary of One-Way Analysis of Variance for Student Time Management (Survey

Questions 5-8) 66

Summary of One-Way Analysis of Variance for Student Expectations (Survey

Questions 9-12) 67

Summary of One-Way Analysis of Variance for Quality of Instruction (Survey

Questions 13-16) 68 


\section{CHAPTER ONE}

Distance education has become a common element within most colleges and universities. Higher education has been forced to create and implement methods of course delivery outside the realm of traditional classroom delivery. The needs of learners continually change with demands of society, making alternative methods of course delivery essential. Today's fast-paced and computer literate society, technological advances and record enrollment for adults returning to school have prompted the emergence of distance education delivery (Arbaugh, 2000; Dixon, 1997; Klesius, Homan \& Thompson, 1997; Spanier, 2000; Tysome, 2001). Distance education delivery includes those courses delivered by means of independent study, telecourses, broadcast, and the Internet. Distance learners face the challenge of increased demands on time, commitments, and lifelong learning associated with both career and family (Cooper, 2000; Fjortoft, 1995; Gibson \& Gibson, 1995; Parker, 1999; Zajkowski, 1997).

There are several advantages of distance education courses. Distance education provides the opportunity for students to access higher education that might not otherwise be available (Cooper, 2000; Fjortoft, 1995; Gibson \& Gibson, 1995). Distance education supplies the flexibility of pursuing a degree at home while allowing the student the ability to determine a suitable pace that matches the student's lifestyle (Jegede, Taplin, Fan, Chan \& Yum, 1999; Towles, Ellis \& Spencer, 1993; Wilkinson \& Sherman, 1989, 1990).

One significant disadvantage of distance education is the high attrition rates experienced by colleges and universities. The literature has identified attrition as an 
area of great concern because distance education courses tend to have higher attrition rates than traditional courses (Brawer, 1996; Carr, 2000; Dille \& Mezack, 1991; Hogan, 1997; Losty \& Broderson, 1980; Morgan \& Tam, 1999; Nesler, 1999; Ozga \& Sukhnandan, 1998; Pugliese, 1994; Snell \& Mekies, 1999; Zajkowski, 1997). Colleges and universities recognize the need to reduce attrition rates in distance education in order to survive in a competitive market (Roweton \& Bare, 1991). Therefore, it is essential that higher education institutions identify the reasons for high attrition rates in distance education courses and devise measures of intervention targeted to retain students (Bink, Biner, Huffman, Greer \& Dean, 1995; Brawer, 1996; Garland, 1993b; Morgan \& Tam, 1999; Nesler, 1999; Roweton \& Bare, 1991; Stephenson, 1997; Weidman, 1985; York, Bollar \& Schoob, 1993).

\section{History of Distance Education}

Distance education is defined as an independent learning approach characterized as self-paced and self-directed in nature in that the student is geographically isolated from the faculty and institution (Chyung, Winiecki \& Fenner, 1998; Eastmond, 1998; Evans, 1986; Holmberg, 1989; Kember, 1989; Klesius et al., 1997; Smith, 1998; Towles et al., 1993, H. S. White, 1999; Wilkinson \& Sherman, $1989,1990)$. Distance education is not a new idea in higher education as it emerged in 1840 in the form of correspondence courses (Abernathy, 1998; Matthews, 1999; Morris, 1999; Peek, 2000).

Growth in Distance Education Programs

The number of distance education programs and courses increased steadily from the mid-1800s to the early 1900 s with the emergence of programs and courses 
in such countries as the United Kingdom, Germany, Japan and the United States (Matthews, 1999; Phillips, 1998). Distance education continued to grow and courses reached a turning point in the late 1960s when a multimedia approach was used in course delivery. Courses were developed that were delivered by radio, television, audio and video materials in addition to the course text (Matthews, 1999; Phillips, 1998). Furthermore, distance courses have transitioned since the late 1990s into computer-based formats that enable courses to be taken in part or exclusively using the Internet.

Colleges and universities have recognized that access to traditional course delivery can be limited because the opportunity to pursue an education is often scarce and exclusive (Hall, 1995; Matthews, 1999). Students may live a great distance from a campus or have fulltime employment obligations that prevent them from attending traditional courses. Additionally, institutions cannot meet the growth in enrollment numbers with the physical limits of a traditional classroom size. Institutions have realized such constraints are nearly impossible to change and therefore, distance education is the delivery modality to meet the needs of the learners.

The number of distance education programs offered by institutions has increased dramatically from the 1980s to present (Matthews, 1999). Degrees and certificates were offered exclusively through distance learning programs at approximately $25 \%$ of the colleges and universities in the United States by late 1995 (Lewis, Farris \& Alexander, 1997; Matthews, 1999). Matthews (1999) reported that 
nearly $58 \%$ of the colleges and universities in the United States offered distance education courses during the 1998-1999 academic year.

The increase in the number of programs being offered by institutions of higher education paved the way for large increases in student enrollment in distance learning courses. Distance education enrollment at colleges and universities exceeded 300,000 students in the mid-1980s and more than doubled to an estimated 763,640 students in the 1994-1995 academic year (Lewis et al., 1997; Matthews, 1999).

\section{Distance Education Purpose and Characteristics}

The original purpose of distance learning programs was to provide an opportunity for pursuit of a college degree by individuals who might not otherwise be able to attend a traditional program at an institution of higher learning (Cooper, 2000; Fjortoft, 1995; Gibson \& Gibson, 1995; Leasure, Davis \& Thievon, 2000; H. S. White, 1999). The purpose of distance education has been modified in part because of the growth in the number of distance education programs offered by colleges and universities as well as the tremendous growth in enrollment in such programs. The purpose has been expanded to include the need for lifelong learning in society and the workplace (Abernathy, 1998; Guernsey, 1998; Parker, 1999; Smith, 1998; Tweney, 1999; Zajkowski, 1997). Skills and knowledge required in today's workplace are constantly changing as technology changes. Technology has improved many of today's family functions such as paying bills online, online banking, and filing taxes via the Internet. Therefore, the need for lifelong learning is essential in keeping up with the rapid changes that affect day-to-day life at the workplace and home. 
Technology assumes an important role in the delivery of distance education programs and serves as a means for interaction between students and faculty. Approximately 19 million households used the Internet in 1997 and use increased to 32 million in 1998 (Hankin, 1999). Spanier (2000) reported that more than 50\% of the homes in the United States had personal computers and more than 130 million people used the Internet in 2000. Spanier went on to predict that usage would increase to 350 million people by 2003 . The projected increase of personal computers in homes and Internet usage by people provides the means by which more students will gain access to higher education.

Terminology in Distance Education

A comprehensive review of the literature reveals an inconsistency in the use of many terms associated with attrition. It is important to note that the literature pertaining to distance education attrition is confusing. Researchers use the following terms: drop out, withdraw, noncompletion, nonpersistence and attrition interchangeably or fail to provide clarity on their use (Bartels \& Willen, 1985; Ekins, 1992, Kerka, 1988). Similarly, researchers use the terms successful, completion and persistence interchangeably (Kerka, 1988). The lack of clear definitions or understanding among the terms makes it difficult to interpret, compare and contrast students who withdraw, fail to complete a course or complete a course accurately.

A successful student can be interpreted as a student that earned a passing grade or a student that completed the course regardless of grade. Nonpersistence may be used for those students who withdrew from a course, failed a course or both. The use of such broad, interchangeable terms in the literature fails to clarify exactly 
what groups of students were included in such studies. Often the literature is unclear as to whether the comparisons of results among studies were similar because the groups were not specifically equated in attrition terminology.

\section{Attrition Rates}

Attrition (the failure to complete a course) is an unsatisfactory outcome for all those involved including the institution, faculty and the student (York, et al., 1993; Zajkowski, 1997). The student has failed to achieve an academic goal while the institution and faculty have failed to retain a distance education student. Perhaps, attrition occurred through lack of service, feedback or knowledge of the student's particular situation. Regardless of the reason, the student, faculty and institution appear to be in a no-win situation in that no one entity gains from the experience.

Attrition has become a major area of concern for distance education providers because researchers have found attrition rates to be higher for distance courses as compared to traditional counterparts (Carr, 2000; Hogan, 1997). Wilkinson and Sherman (1989) reported noncompletion in distance education courses to be somewhere between $30 \%$ and $70 \%$. Program directors in the same study estimated that noncompleters and nonstarters ranged from $30 \%$ to $45 \%$. In a similar study, Hogan (1997) found that the distance education withdrawal rate was $21 \%$ in comparison to the traditional education rate of $19 \%$.

Researchers have identified factors that lead to attrition including lack of faculty-student communication, inadequate time management, unrealistic expectations, and quality of instruction (Chyung et al., 1998; Cooper, 2000; Frew \& Weber, 1995; Minich, 1996; Saba, 2000; Wilkinson \& Sherman, 1989). Colleges and 
universities should examine two key factors directly associated with attrition. First, the causes of attrition vary at each institution because of demographic factors and the climate of the institution (Roweton \& Bare, 1991; York et al., 1993). It is possible that some courses such as chemistry and physics may be very difficult to take through a distance education course because these courses require a high level of mathematical ability and the use of laboratories. Secondly, distance education failure or course withdrawal is not caused by one single factor, but a culmination of many factors (Morgan \& Tam, 1999; Parker, 1999; Saba, 2000). The distance learner typically manages a career, education and family simultaneously and any combination of events can lead to failure or withdrawal from the course.

\section{Student Success in Distance Education}

The literature indicates that successful students in distance education courses experience satisfactory faculty-student communication, have adequate time management skills, hold realistic expectations about the course(s), and experience satisfactory levels of instruction (Chyung et al., 1998; Cooper, 2000; Frew \& Weber, 1995; Minich, 1996; Saba, 2000; Wilkinson \& Sherman, 1989).

Interaction between faculty and students is an essential part of the learning process in both traditional and distance courses (Anderson \& Garrison, 1995; Hall, 1990; Hillman, Willis \& Gunawardena, 1994; Inman \& Kerwin, 1999; Leasure et al., 2000; Tweney, 1999). Faculty-student interaction becomes vital when a learner is struggling with difficult material and needs clarification or assistance. The interaction may be in the form of a phone call, electronic mail, fax or a face-to-face meeting. The interaction becomes essential in mastering the information to move forward in 
the course. An unsatisfactory level of faculty-student communication can be detrimental to the success of the student.

Despite the need for flexibility and convenience, student time management affects persistence in distance learning courses (Garland, 1993b). Typically, problems in time management are related to multiple roles and procrastination (Garland, 1993a, 1993b; Guernsey, 1998; Janssen \& Carton, 1999; Jegede et al., 1999; Leasure et al., 2000; Minich, 1996; Morgan \& Tam, 1999; Prather \& Hand, 1986; Saba, 2000; Taplin \& Jegede, 2001; Wang \& Newlin, 2000; Wilkinson \& Sherman, 1989, 1990). Distance learners typically hold down fulltime jobs, take college classes and have families that place obligations on the student that must somehow be balanced. The necessity of balancing many responsibilities can become overwhelming to a student who lacks adequate time management skills and may contribute to failure or withdrawal from a distance course.

Students enroll in distance education courses with preconceived ideas and expectations about the courses from peer opinions or reading literature on the course. Researchers have supported the idea that persistence is affected by a student's unrealistic expectations (Chyung et al., 1998; Cooper, 2000; Towles et al., 1993; C. White, 1999; Wilkinson \& Sherman, 1989; York et al., 1993). Often, a student believes a course will be relatively easy because it involves writing a paper or completing take-home examinations. Typically, courses that involve writing a paper include many constraints on the quality and style of the paper in that it is of research quality. In addition, students have the privilege of using resources such as a textbook to complete the take-home examinations that are often more difficult. 
Researchers found that the quality of instruction in distance education courses was a factor that affected persistence (Frew \& Weber, 1995; Inman \& Kerwin, 1999; Wilkes \& Burnham, 1991; York et al., 1993). Studies have demonstrated that the quality of instruction is associated with promptness of materials received by the student, overall quality of the course as perceived by the student and the changing role of faculty teaching distance learning courses (Alexander, 1999; Carr, 2000; Frew \& Weber, 1995; Inman \& Kerwin, 1999; Leasure et al., 2000; Wilkes \& Burnham, 1991; York et al., 1993). The distance faculty member assumes a different role as compared to faculty of traditional courses because the course is no longer "teacher-centered", but "student-centered". The faculty member must present the material in a different way and provide support and encouragement as the student progresses through the course.

Impact of Distance Education on College and University Administrators College and university administrators have been greatly affected by the growth and changes in distance education. Administrators have been challenged to create new and innovative ways of meeting the needs of today's distance learners (Cooper, 2000; Fjortoft, 1995; Gibson \& Gibson, 1995). This challenge accompanies the need for assessment of distance education courses and programs offered. The assessment of programs reveals useful information such as attrition rates and student demographics. It is essential that administrators have a clear picture of what types of distance learners are served by the institution.

Administrators must create programs and plans of intervention to decrease student attrition in distance education (Bink et al., 1995; Brawer, 1996; Garland, 
1993b; Morgan \& Tam, 1999; Nesler, 1999; Roweton \& Bare, 1991; Stephenson, 1997; Wade, 1999; Weidman, 1985; York et al., 1993). Administrators can analyze the information and create plans to address problem areas. Distance learners may never visit the campus and therefore, it is vital that the administrators carefully plan programs and intervention methods that will meet the distance learner's needs.

The researcher for this study is a distance education faculty member and the information obtained in the study will be of vital importance. The results of the study will be very helpful in creating a profile of a successful distance education student. The profile will enable the researcher to identify strengths and challenges of the distance courses. Therefore, the researcher will be able to make changes in the courses to compliment the strengths and reduce the challenges identified by the study.

\section{Statement of the Problem}

The purpose of this study was to identify the predictors of success in distance education courses. The study measured the level of student success in conjunction with student perception of the variables identified by a review of literature pertaining to distance education.

The independent variables for this study include faculty-student communication, student time management, student expectations and quality of instruction. The dependent variable for this study is level of student success in the distance course. 


\section{Research Questions}

The purpose of this study is to identify the predictors of success in distance education courses. The study will answer the following questions:

1. What is the relationship, if any, between faculty-student communication and the level of student success in distance education courses?

2. What is the relationship, if any, between student time management and the level of student success in distance education courses?

3. What is the relationship, if any, between student expectations and the level of student success in distance education courses?

4. What is the relationship, if any, between quality of instruction and the level of student success in distance education courses?

\section{Operational Definitions}

The following operational definitions were used in accordance with the purpose of this study:

1. Level of student success - The student reported a final course grade of A, $\mathrm{B}, \mathrm{C}, \mathrm{D}, \mathrm{F}$ or $\mathrm{W}$ on the survey questionnaire. A successful student was defined as a student who earned a grade of $A, B$ or $C$ in the course.

2. Faculty-student communication - The level of satisfaction of the communication between the faculty and student as indicated by responses on the survey questionnaire.

3. Student time management - The student's perception of his or her time management, multiple roles, and procrastination as indicated by responses on the survey questionnaire. 
4. Student expectations - The student's perception of expectations as indicated by responses on the survey questionnaire.

5. Quality of instruction - The student's perception of the quality of instruction as indicated by responses on the survey questionnaire.

\section{Significance of Study}

College and university administrators perform seven administrative functions according to Gulick and Urwick (1969). The seven administrative functions include planning, organizing, staffing, directing, coordinating, reporting, and budgeting (Gulick \& Urwick, 1969). Identification of the characteristics of the successful distance learning student will enable administrators to use the seven administrative functions to strategically plan intervention measures to decrease attrition (Bink et al., 1995; Brawer, 1996; Garland, 1993b; Morgan \& Tam, 1999; Nesler, 1999; Roweton \& Bare, 1991; Stephenson, 1997; Weidman, 1985; York et al., 1993).

Enrollment services, academic services, and distance-learning administrators can assess the characteristics of a successful distance education student to determine problem areas that need to be addressed at the respective institution. Assessment of the problem areas will allow the administrators to devise a plan of intervention with a focus on reducing attrition. The collaboration of enrollment services, academic services and distance learning is imperative to provide a well-rounded plan that includes various areas of expertise.

The distance-learning administrator is typically held accountable for distance attrition rates and therefore, it is logical that he or she be responsible for organizing and coordinating the plan devised by all three constituents. The administrator can 
develop an organizational scheme and identify the relationships found within the scheme and coordinate it with the enrollment services and academic services administrators. A collaborative effort by administrators involved may be used to delineate and integrate the activities involved at each level of the plan and organizational scheme. It is at this point that the group of administrators should also develop a timeline for implementation of the intervention plan.

The enrollment services, academic services, and distance-learning administrators handle staffing functions within their respective areas or divisions. The staffing function not only includes designation of current staff or hiring new staff for the plan of intervention, but also providing the training of the individual(s) selected and "maintaining favorable conditions of work" (Gulick \& Urwick, 1969, p. 13).

Once the administrators have collaboratively established a plan, organized, coordinated, and provided staffing for the methods of intervention the focus must be turned to the directing function. The distance-learning administrator assumes various roles within this function in that he or she must stress the importance of the plan, ensure that training has been provided to staff and motivate staff to perform the activities and assume the responsibilities of the plan. It is vital that all staff involved in carrying out the plan of intervention know what problems have been experienced, why the plan was created and how it will work in conjunction with other areas, divisions and staff.

The distance-learning administrator typically performs the budgeting function because the measures of intervention are to address a problem specific to that area 
or division. The administrator must account for the cost of the intervention plan within the institutional budget. Many things must be considered when budgeting, such as length of intervention plan, cost of implementation, new staff position(s), and promotions or raises to existing staff for a role in the intervention plan.

\section{Summary}

Distance education courses provide today's learner with the opportunity to seek an education outside the traditional classroom (Arbaugh, 2000; Dixon, 1997; Klesius et al., 1997; Spanier, 2000; Tysome, 2001). Education is no longer restricted to on-campus facilities. Distance education has created a campus without walls in that the student has the flexibility to create a schedule to complete curriculum requirements that best suits the student's busy lifestyle. Learning can happen at the time and place convenient for the student.

Convenience and flexibility are the two most common reasons that students cite for enrolling in distance learning courses (Cooper, 2000; Fjortoft, 1995; Gibson \& Gibson, 1995). The flexibility of such courses challenges today's learner with the task of managing an education, family and career obligations and responsibilities. It is common practice for distance learners to take exams in the middle of the night or on a lunch break at work. Some students even write papers while traveling during a business trip.

The literature revealed that higher attrition rates are found in distance learning courses when compared to traditional courses (Brawer, 1996; Carr, 2000; Dille \& Mezack, 1991; Hogan, 1997; Losty \& Broderson, 1980; Morgan \& Tam, 1999; Nesler, 1999; Ozga \& Sukhnandan, 1998; Pugliese, 1994; Snell \& Mekies, 1999; 
Zajkowski, 1997). Therefore, it is paramount that colleges and universities identify the causes of attrition in distance education courses and implement preventive measures to curb high attrition rates. Institutions should analyze and identify the characteristics of a successful distance education student. Colleges and universities can use the characteristics of a successful student in distance education programs to create a profile and devise and implement intervention methods to decrease attrition (Bink et al., 1995; Brawer, 1996; Garland, 1993b; Morgan \& Tam, 1999; Nesler, 1999; Roweton \& Bare, 1991; Stephenson, 1997; Weidman, 1985; York et al., 1993).

\section{Limitations of Study}

1. The study was limited to Mountain State University. Therefore, generalizability to other institutions was compromised.

2. The accuracy of participant responses on the self-reported survey limited the study (Kerlinger, 1986).

3. A single instrument was used to collect data for each variable (Kerlinger, 1986).

4. The study was limited to students enrolled in undergraduate distance education courses and did not consider graduate students.

5. The study was limited to the enrollment during the summer and fall 2001 terms at Mountain State University.

6. The reliability and validity of the research instrument imposed a limitation on the findings of this study. 
7. The study was limited in that the use of technology incorporated into some of the Independent Study courses was not examined. 
CHAPTER TWO

Review of the Literature

The purpose of this chapter is to provide an understanding of the body of research that serves as the foundation for the variables selected for this study. The history and transformation of distance education courses is discussed to create a framework for the sequence of events that have contributed to the distance education movement and have shaped today's distance education courses. Areas of particular interest include the purpose and characteristics, attrition terminology and attrition rates of distance education. A comprehensive review of the literature revealed four factors that predict student success in distance education courses: faculty-student communication, student time management, student expectations and quality of instruction. Each factor is examined in detail as it relates to this study.

History of Distance Education

Distance education has made its way to the forefront of higher education as the latest "wave of the future"; however, it is not a new concept (Abernathy, 1998; Matthews, 1999; Morris, 1999; Peek, 2000). According to Matthews (1999) and Phillips (1998), Sir Isaac Pitman was credited with the development of correspondence courses offered through the mail in 1840. Pitman foresaw a need to deliver instruction to an audience that was limitless in the traditional respect of classroom confinement and reach out to a large number of students in various locations (Matthews, 1999; Phillips, 1998).

From the inception of the first correspondence course to present, distance education has evolved and experienced exponential growth in the number and types 
of courses offered as well as the number of institutions offering such courses. Countries such as the United Kingdom, Germany, Japan and the United States experienced steady growth in the number of distance education programs and courses from the mid-1800s to the early 1900s (Curran, 1997; Matthews, 1999). The University of Chicago was the first institution to create and establish a department of correspondence teaching in the early 1900s (Kember, 1989; Matthews, 1999). Shortly thereafter, in 1911, a department of external studies was established at the University of Queensland located in Australia (Matthews, 1999).

The growth of distance education programs continued through the mid-1900s. Distance learning programs reached a milestone in development when a "mixed-media" approach to delivery was introduced in 1969 with the founding of the United Kingdom's Open University (Matthews, 1999). The United Kingdom's Open University and the British Open University were denoted as pioneers in distance education because the institutions brought distance learning to the forefront of higher education while enhancing and elevating the profile to a new level using the mixed-media approach (Curran, 1997; Matthews, 1999).

\section{Distance Education Opportunities}

The distance learning movement occurred in response to two stimuli in particular. First, colleges and universities identified problems with scarcity and exclusivity in that opportunities for education were far and few in number and access was limited (Hall, 1995; Matthews, 1999). Secondly, the structure of the traditional university made it nearly impossible to accommodate the large growth in enrollment. Therefore, the university was unable to meet the growing needs of its current 
students and potential students (Hall, 1995; Matthews, 1999). Distance education proved to be the vehicle to reach out to mass numbers of potential students by offering the opportunity to pursue a college degree rather than offering seats to already crowded traditional classrooms (Matthews, 1999). Students are often prevented from enrolling in traditional courses because of obligations at work and home or the geographical distance from campus. Institutions have recognized that distance education is the method of delivery to respond to such constraints that cannot be changed.

The time period from 1969 to 1989 was marked by the addition of four open universities in Europe and more than twenty additional distance education universities worldwide (Matthews, 1999). The two decades were characterized by large increases in the number of distance learning programs established at college and universities and increased growth in enrollment numbers in such programs.

\section{Distance Education Purpose and Characteristics}

The continual growth in the number of distance learning programs offered by colleges and universities and increased enrollments in such programs have modified the purpose of distance education and the role of distance educators. The initial purpose of distance learning programs was to provide the opportunity for individuals to pursue a college education or advanced degree outside the traditional classroom walls, who may not otherwise be able to attend a traditional program (Cooper, 2000; Fjortoft, 1995; Gibson \& Gibson, 1995; Leasure, Davis \& Thievon, 2000; H. S. White, 1999). 
Many distance education courses can be completed via the Internet, creating a virtual college or university at any time and location the student chooses (Ballon, 1999; Jerome, 1999; Neumann, 1998; Weber, 1999). The purpose of distance learning programs has expanded to include the need for lifelong learning in society and the workplace (Abernathy, 1998; Guernsey, 1998; Parker, 1999; Smith, 1998; Tweney, 1999; Zajkowski, 1997). Distance education offers a means by which working adults can sharpen skills or "gain or increase their formal knowledge and qualifications" (Zajkowski, 1997, p. 12).

Role of technology. Technology plays a vital role in the delivery of distance education programs and courses by serving as a means for communication between faculty and students. The literature emphasizes that for learning to occur, faculty-student interaction is required (Anderson \& Garrison, 1995; Hillman, Willis \& Gunawardena, 1994; Inman \& Kerwin 1999; Tweney, 1999). Technology, such as that reflected in web-based courses, can be used to provide the communication medium necessary to promote faculty-student interaction. Further, these technologies can provide the vital interaction without the physical limitations inherent in the classroom only deliveries.

Hankin (1999) asserted that Internet use at home was approximately 19 million in 1997 and nearly doubled in 1998 . More than $50 \%$ of the homes in the United States were equipped with personal computers and more than 130 million people used the Internet in 2000 according to Spanier (2000). Spanier projects that Internet usage will increase to include 350 million people by the year 2003. The 
predicted increase in the number of personal computers in households and Internet use will enable more people to gain access to higher education.

Role of the distance educator. Distance education providers must strive to respond quickly to the needs of today's learners and the needs of tomorrow's learners (Spanier, 2000). In doing so, the role of the distance educator or instructor has been modified to include teaching students how to use the technology incorporated into the course (Hillman et al., 1994; Inman \& Kerwin, 1999). Strategic management in the course remains the key role for the distance educator (Stone, 1992). The distance educator should be concerned with meeting the needs of the learner in addition to those of the college or university as well as focusing on instructional outcomes (Smith, 1998; Stone, 1992). The changing roles of the distance educator have facilitated institutions to establish goals to continue offering a quality product while meeting the needs and resolving the problems of distance learning students (Frew \& Weber, 1995).

\section{Terminology in Distance Education}

The large increase in distance learning programs, huge influx of enrollment and modifications of purpose and role prompted researchers to investigate attrition rates of distance education courses as compared to traditional courses. It is important to note that a comprehensive review of the literature revealed an inconsistency in the use of many terms associated with attrition. Therefore, the literature pertaining to distance education attrition is confusing. Terms such as dropout, withdrawal, noncompletion, unsuccessful, nonpersistence and attrition are used interchangeably or the researchers fail to provide a clear and concise definition 
for each term used in the studies (Bartels \& Willen, 1985; Ekins, 1992; Kerka, 1988). Researchers use the terms persistence, successful and completion interchangeably as well (Kerka, 1988).

The task of interpreting and comparing the literature becomes difficult when there is lack of clear definition or understanding in the use of attrition terminology in distance education. Persistence can be interpreted as a student that completes a course regardless of the grade earned or a student that receives a passing grade in the distance course. An unsuccessful student may be viewed as a student that receives a failing grade, withdrew from the course or both. The inconsistent use of attrition terminology in the literature fails to clearly indicate which group of students is represented by the terms used in such studies. In addition, because the literature fails to clarify the groups used in the studies, it becomes unclear as to whether the comparisons of results among studies were accurate because of possible inequality.

\section{Attrition Rates}

Colleges and universities are concerned with the attrition rates associated with distance education courses (Brawer, 1996; Carr, 2000; Hogan, 1997; Nesler, 1999). Attrition and withdrawal rates for distance education courses are generally higher than those of traditional courses (Carr, 2000; Hogan, 1997). The University of Central Florida reported a distance education attrition rate of $9 \%$ in comparison to the traditional rate of $5 \%$ (Carr, 2000). Similarly, the Dallas County Community College showed an $11 \%$ to $15 \%$ higher attrition rate for distance education courses as compared to traditional courses (Carr, 2000). Tyler Junior College observed higher attrition rates for distance education courses in comparison to traditional 
courses. The distance education attrition rate was $42 \%$ while that of the traditional courses was $29 \%$ (Carr, 2000).

Wilkinson and Sherman (1989) studied two distance education programs that were determined to be diverse in nature. Administrators and professors of the two programs were interviewed and the main topic of interest was noncompletion of distance education courses. Distance educators estimated that $30 \%$ to $45 \%$ of the distance education students never begin the courses or those students who begin the courses fail to complete the courses (Wilkinson \& Sherman, 1989). South Carolina's Technical College of the Lowcountry assessed the withdrawal rates of distance education students and traditional students. The study concluded that the withdrawal rates for distance education courses were higher than that of the traditional courses. Specifically, the withdrawal rate for the distance education courses was $21 \%$ while the withdrawal rate for traditional courses was 19\% (Hogan, 1997).

\section{Student Success in Distance Education}

The literature has identified that faculty-student communication, student time management, student expectations, and quality of instruction are factors that contribute to distance education attrition rates (Chyung, Winiecki \& Fenner, 1998; Cooper, 2000; Frew \& Weber, 1995; Hogan, 1997; Minich, 1996; Saba, 2000; Wilkinson \& Sherman, 1989). There are two key concepts directly associated with distance education attrition that should be considered by distance education providers. First, there is great variance in demographic factors and climate at each institution (Roweton \& Bare, 1991; York, Bollar \& Schoob, 1993). Therefore, the 
causes of attrition are not universal at all colleges and universities, but institutionspecific. Secondly, distance education attrition results as a culmination of factors and is not caused by a single factor (Morgan \& Tam, 1999; Parker, 1999; Saba, 2000).

Faculty-Student Communication

The first variable identified by the literature indicates that the communication between faculty and students is an essential part of the learning process for both traditional and distance courses (Anderson \& Garrison, 1995; Hillman et al., 1994; Inman \& Kerwin, 1999; Leasure et al., 2000; Tweney, 1999). Distance courses lack the face-to-face interaction between faculty and students found in a traditional classroom. Therefore, the faculty-student interaction assumes a vital role in the success of the distance student. Students who struggle with difficult material or need feedback concerning performance on assignments and exams rely on such communication. Communication may occur as a phone call, electronic mail, fax or a face-to-face meeting. Regardless of the medium, faculty-student communication is an important factor in contributing to the success of distance learning students.

Communication between faculty and students should occur frequently and be of an acceptable quality to the student (Alexander, 1999; Bean, 1982; Prather \& Hand, 1986; Terenzini \& Pascarella, 1980; Saba, 2000). Students want immediate feedback concerning questions and course performance especially since there is a distance barrier separating the student and faculty (Alexander, 1999; Saba, 2000). Saba stated that students who receive frequent feedback tend to be more interested in going on to the next course assignment or exam. Providing fast feedback on 
assignment and exam performance is an effective management strategy to maintain student motivation and interest in the course (Saba, 2000). Similarly, Bean (1982) contended that communication with faculty gives the attention, information, and encouragement needed by some students to complete a distance course.

Establishing communication. Several studies have found that faculty-initiated communication has a positive effect on persistence in distance education courses (Hillman et al., 1994; Inman \& Kerwin, 1999; Towles, Ellis \& Spencer, 1993). A study by Towles et al. (1993) investigated the effect of faculty-initiated communication on distance course completion rates at Liberty University. The study included 120 students enrolled in four general education courses: biology, government, history and music. The courses were offered solely through distance learning and were video-based in nature. The Liberty University School of Lifelong Learning (LUSLL) located in Lynchburg, Virginia established a program of facultyinitiated contact in the four general education courses. The program required faculty to initiate contact with the student by using the telephone during the course.

The experimental and control groups consisted of 15 students from each of the four general education courses. The groups were similar in GPA, age and other demographic variables. The experimental group was exposed to the program of faculty-initiated contact via the telephone throughout the course. The control group did not receive faculty-initiated phone calls during the course.

Data were collected using an ongoing course survey. Analysis of the data revealed that the students in the control group demonstrated a completion rate of $36 \%$ as compared to the $64 \%$ completion rate exhibited by the experimental group 
(Towles et al., 1993). Results of the study confirmed the positive effect of faculty-student communication on the success of distance students.

Researchers have investigated the effects of establishing faculty-student communication by using an orientation session at the beginning of a distance education course. Hillman et al. (1994) studied a group of graduate students enrolled in distance education courses offered by the University of New Mexico at Albuquerque and Los Alamos. The distance courses were part of a distance education pilot program that used a software system called Worldlinx audiographics as well as email (Hillman et al., 1994). All students were required to attend the four-hour orientation session taught by the instructors and distance education coordinators during the first week of class.

The purpose of the orientation session was to help students understand the technology used in the courses. Therefore, the instructors assumed the role of "humanizing" the technology for the students (Hillman et al., 1994; Inman \& Kerwin, 1999). Each orientation session included a brief introduction to the software components immediately followed by practical hands-on activities using the system. Students were organized into teams at the two campuses and engaged in various assigned activities designed to use the software components. One specific activity was participating in a game of Pictionary that required the students to use the more advanced system components and knowledge gained form the introductory portion of the orientation session.

Students participated in an evaluation at the end of the orientation session. The study concluded that students were very involved in the activity and especially 
enjoyed the game of Pictionary (Hillman et al., 1994). The study also found that learners believed the activity was an easy yet relaxing way to learn how to actually use the software components (Hillman et al., 1994).

The underlying note of importance is that the orientation session established faculty-student communication. The course mandate to attend the orientation session accomplished several things. First, students were able to meet the faculty face-to-face as well as peers enrolled in the same courses. The orientation session allowed students to become familiar with the technological delivery of the course using relaxing and enjoyable activities that encourage interaction. Finally, the foundation for communication between faculty and student was established upon which future communication could be built.

Inman and Kerwin (1999) examined both faculty and students to determine the level of satisfaction of the distance learning experience. The faculty and students were surveyed separately during the fall 1996 term at the University of Kentucky Community College system. Eleven faculty that taught telecourses were included in the study. The telecourses consisted primarily of video material and instructorgenerated materials (Inman \& Kerwin, 1999). Six different telecourses were represented in the faculty sample. An orientation session was scheduled to provide training for the telecourses; however, it was not mandatory that students or faculty attend. A survey was sent to faculty approximately two-thirds of the way through the course. The survey revealed that there was very little faculty attendance at the orientation session and there was no faculty mentoring provided to teach a telecourse (Inman \& Kerwin, 1999). 
A survey was sent to 364 students enrolled in the six different telecourses at the same time as the faculty survey. Analysis of the data determined that the quality of on-campus sessions accounted for $9 \%$ of the variance in instructor ratings (Inman \& Kerwin, 1999). The survey results indicated that only $57 \%$ of the students attended the orientation session and overall $76 \%$ of the students who attended the orientation session rated the session as somewhat helpful or very helpful (Inman \& Kerwin, 1999). Most importantly, the ratings of the orientation session were directly related to the instructor ratings (Inman \& Kerwin, 1999). As expected, high ratings on the orientation session accompanied high ratings of the instructor.

Additionally, analysis of the data denoted that availability of the faculty accounted for $5 \%$ of the variance in ratings of the instructor (Inman \& Kerwin, 1999). The study indicated that $13 \%$ of the students found the faculty to be somewhat available while $82 \%$ of the students stated the faculty was very available throughout the course (Inman \& Kerwin, 1999). Therefore, the higher the satisfaction of instructor availability experienced by the student, the higher the rating given to the instructor.

Satisfactory communication. Several studies have demonstrated that a satisfactory level of faculty-student communication contributes to the success of distance education students (Garland, 1993b, Minich, 1996; Morgan \& Tam, 1999). One such study used ethnography to examine the barriers to persistence and student withdrawal from distance education courses. Garland (1993b) studied a sample of 47 students enrolled in five introductory courses in the natural resource sciences at the University of British Columbia. More specifically, the sample 
consisted of 17 students who had withdrawn from the courses and 30 students who persisted. The introductory courses varied in the media used in each course. Some courses were text only while others used such things as video and television broadcast. In addition, a completion rate of $66 \%$ was calculated for the group (Garland, 1993b).

Interviews were conducted with each student in a convenient location to the student, which usually was the student's home. Garland (1993b) used the inductive approach during the interview session with the first question focused on the student's experience as a distance education student. Additional questions were formulated from the responses by using the unstructured and informal approach to interviewing participants. The data collected from the interviews with participants were coded and assigned to one of four categories of potential barriers to persistence: situational, institutional, dispositional and epistemological (Garland, 1993b). Situational barriers are considered changes in life circumstances such as family and career while institutional barriers center around experiences with the higher education institution. Dispositional barriers are comprised of personal problems that can impact the student. Epistemological barriers are barriers directly associated with the content discipline or difficulty of the content.

Communication between faculty and student is found in the category of institutional barriers of persistence. Analysis of interview data revealed that some students were not satisfied with limited telephone hours, failure of the faculty to be available during designated hours and lack of faculty-initiated contact (Garland, 1993b). Some students reported that the lack of optimism, caring for the student, 
support and courtesy were frustrating and unsatisfactory (Garland, 1993b). One student specifically cited the condescending nature of the instructor as the primary reason for withdrawal from the course (Garland, 1993b). Another area of concern identified by students was the slow turnaround time on course assignments, lack of explanation for errors and illegible writing (Garland, 1993b). The study clearly found an unsatisfactory level of faculty-communication affects the decision to persist or withdraw from a distance education course.

In a similar study, Minich (1996) examined a population of 2220 students enrolled in telecourses at the Florida Community College at Jacksonville in the 1995 winter term. The purpose of the study was twofold: (1) to uncover the real reasons that students withdrew from distance education courses and (2) to evaluate faculty support, administration and student services. The study was comprised of two groups of students and used two different surveys. Both instruments were created by the community college as a part of the ongoing assessment of the distance education program.

The withdrawal rate from the telecourses was determined to be $16 \%$ of the total population (Minich, 1996). Therefore, the Student Withdrawal Survey was mailed to 355 students who withdrew from the courses to identify the reasons for withdrawal and what the college could have done to prevent the withdrawal (Minich, 1996). A survey return rate of $18 \%$ was experienced with only 65 students responding to the survey. Regardless of the very low return rate, results indicated that $68 \%$ of the students had not attempted to communicate with the faculty (Minich, 1996). In addition, $20 \%$ of the students stated unsatisfactory faculty support was a 
primary reason for withdrawal from the course (Minich, 1996). The second part of the study used the End of Term Survey. The End of Term Survey was used to evaluate administration, faculty support and telecourse design. A $19 \%$ return rate for the survey was calculated with 424 students responses (Minich, 1996).

Analysis of the survey responses demonstrated that $77 \%$ of the students found satisfactory telephone availability of faculty (Minich, 1996). Additionally, 83\% of the students received prompt feedback and $82 \%$ stated that the faculty welcomed questions (Minich, 1996). Lastly, Minich (1996) discovered 78\% of the respondents felt that the faculty was helpful throughout the course. The results of both surveys used in the study concurred that satisfactory faculty-student communication has a positive effect on student success in distance education courses.

In a study by Morgan and Tam (1999), qualitative methods were used to expose the real reasons or barriers that contribute to student nonpersistence in distance education courses. Similar to the Garland (1993b) study, unstructured interviews with students were used to collect data. Morgan and Tam (1999) examined a group of 118 students enrolled in a horticulture course offered exclusively as a distance-learning course. The purpose of the study was to identify reasons for nonpersistence and gain an understanding for the experiences and circumstances of the students. The population was comprised of nine students classified as not persisting and 99 students who were persisting in the distance course. Random selection was used to choose nine students from the group of persisting students who would receive an interview. All of the nonpersisters were 
interviewed in the study. Telephone interviews were used in lieu of face-to-face interviews if scheduling conflicts could not be resolved.

The data were collected, coded and categorized into the four potential barriers to persistence as was done in the Garland (1993b) study: situational, institutional, dispositional and epistemological. The relevant category was institutional barriers and the results indicated that approximately $66 \%$ of the nonpersisters mentioned communication with faculty as a barrier to persistence (Morgan \& Tam, 1999). Both persisters and nonpersisters cited insufficient and unsatisfactory communication with academicians as a barrier to persistence (Morgan \& Tam, 1999). Hence, faculty constitutes the largest portion of the academic realm and communication is a major concern as indicated by the students surveyed. Again, satisfactory levels of faculty-student communication serve as an important factor that contributes to the success of distance learners.

\section{Student Time Management}

The second variable identified by the literature was student time management. Students with busy lifestyles typically enroll in distance education courses because of the flexibility and convenience in scheduling (Jegede, Taplin, Fan, Chan \& Yum, 1999; Towles et al., 1993; Wilkinson \& Sherman, 1989, 1990). Distance education students usually have families, take college courses and hold fulltime jobs that place various responsibilities on the students who must somehow balance an education, career, and family. Students who lack time management skills or procrastinate regularly may jeopardize the level of success in distance education courses. Students often become overwhelmed in balancing career, family 
and education when there is a lack of time management skills or the propensity to procrastinate exists (Saba, 2000).

Multiple roles. Many students face the challenge of trying to find time to devote to studying in addition to various career and family demands (Garland, 1993b; Herrmann, 1988; Minich, 1996; Morgan \& Tam, 1999; Towles et al., 1993). Many studies have been conducted to examine the effect of multiple roles on distance education student success. The purpose of one study was to observe the changing perceptions of distance learners while the students continued to maintain employment during the distance courses. Herrmann (1988) interviewed 25 students enrolled in distance education courses in an Associate Diploma in Engineering Program. Students were selected for the sample if they were in level 2, 3 or 4 of the mechanical or electrical engineering programs and were available for a campus interview.

The conceptual framework for the study was comprised of primary socialization, secondary socialization, resocialization, commitment and changes in perceptions and control over career (Herrmann, 1988). Primary socialization involves the social skills obtained in childhood whereas secondary socialization includes the social learning that occurs at school and work during the adult years. Resocialization consists of the social learning of one's profession and occupation. Adjustment occurs as a person moves from one role to another and the resulting changes of such movement. People who participate in activities while exhibiting consistent behavior constitute commitment (Herrmann, 1988). 
Interviews were conducted and results suggested that the longer a student is in a distance course, the greater the investments become for the student and therefore, the loss becomes greater should the student fail to complete the course (Herrmann, 1988). Investments, according to Herrmann (1988), include such things as time, money and relationships with family. The results also indicated that students often cite personal problems such as family, career and self for failure to complete the course when there is actually difficulty with the course material or time management of the course (Herrmann, 1988). It appears that students are more willing to blame the reason for noncompletion on personal problems instead of accepting responsibility for the lack of time management skills. Perhaps, it is easier to state personal problems as the primary reason for noncompletion because nearly everyone experiences such problems and it would be less damaging to one's pride (Herrmann, 1988).

In a study by Garland (1993b), a sample of 47 students at the University of British Columbia was examined to identify the barriers to persistence. The students were enrolled in introductory courses in the natural sciences, all of which used various media in the distance course delivery. The sample was comprised of 17 students who withdrew from the courses and 30 students who completed the courses.

Interviews were used to collect data at a time and place convenient to the participants. Garland (1993b) coded the data collected and categorized the results into one of four categories of potential barriers to persistence: situational, institutional, dispositional and epistemological. The category of dispositional barriers 
contained the data pertaining to the stress of multiple roles and student time management. Results indicated that students identified the stress of multiple roles as a problem with persistence (Garland, 1993b). The student must deal with the stress of the everyday roles in addition to the stress of being a student. The problem of time management becomes apparent when the student has to prioritize time for activities deemed important in lieu of other activities. The results of the study provided evidence that students who persisted prioritized their time effectively while the students who withdrew did not. Therefore, the study asserted that student time management is a contributing factor in the success of the distance student.

In a similar study, Towles et al. (1993) observed the effects of multiple roles on the success of distance education students. The study consisted of 120 students enrolled in four general education courses offered solely through a distance-learning program at Liberty University. Faculty were required to initiate contact with students using the telephone as mandated by the program.

Fifteen students from each course were assigned to the experimental and control groups. The researchers stated the two groups were similar in demographic variables. The experimental group experienced the program of faculty-initiated contact while the control group received no treatment.

An ongoing course survey was used to collect data. Towles et al. (1993) found that $60 \%$ of the students who had withdrawn from the courses wanted to enroll again. However, the students were unable to do so because of the stress and time constraints of the multiple roles with career, family and education. The results of this study concur with the study by Garland (1993b) in that the stress of managing 
multiple roles greatly impacts the success of the distance student. More specifically, increase in stress levels tends to contribute to student withdrawal from distance courses.

A study by Minich (1996) provided insight into the multiple roles of distance students in addition to the findings pertaining to faculty-student communication. The study occurred in the winter term of 1995 at the Florida Community College at Jacksonville. A population of 2220 students was enrolled in telecourses that particular term. Students were grouped according to whether the student withdrew from a telecourse or completed the telecourse. Two instruments developed by the community college were used as part of the ongoing assessment of distance education courses.

Minich (1996) reported that $69 \%$ of the students surveyed indicated that withdrawal from the telecourse resulted from personal reasons that included family responsibilities, career changes and illness of family or self. Students are faced with the task of managing a career, family and education. The stress of multiple roles challenges students to prioritize all aspects of life in accordance with the time available to the students. The study provides evidence that the stress of multiple roles negatively impacts the success of distance students because the students typically withdrawal from the course.

Student time management as related to multiple roles of the distance education student was the central focus of a study by Morgan and Tam (1999). The purpose of the study was to identify the real reasons or barriers that contribute to nonpersistence of the distance student. A group of 118 students enrolled in a 
horticulture course offered solely through distance education was examined in the study. Specifically, 99 students were designated as persisting in the course and 9 students were not persisting. Nine students from the "persisting" group were selected for the sample by means of random selection and all the "nonpersisting" students were included in the sample.

Collection and analysis of data occurred using the same categories of potential barriers to persistence as found in the Garland (1993b) study: situational, institutional, dispositional and epistemological. The dispositional category revealed insight into the time management of the students. The study demonstrated that $56 \%$ of the participants cited time management as the reason for nonpersistence in distance courses (Morgan \& Tam, 1999). Specifically, distance students constantly try to maintain a balance among a career, family and education. Some students find a satisfactory balance that enables educational studies to continue while other students never establish a balance (Morgan \& Tam, 1999). The results of this study confirm that student time management related to multiple roles is a common problem in the success of the distance learner.

Procrastination. Problems with student time management and course pacing contribute to the stress level of the student as well as procrastination (Garland, 1993b). Procrastination is defined as the act of postponing tasks needlessly (Janssen \& Carton, 1999; Leasure et al., 2000; Saba, 2000; Wilkinson \& Sherman, $1989,1990)$. Students become bored or frustrated depending on which aspect of time management they experience difficulty with and eventually, most fail the course or withdraw. Time management regardless of whether it is lack of the skill, pacing 
difficulty or procrastination has been clearly defined in the literature as a factor that affects persistence (Leasure et al., 2000; Wilkinson \& Sherman, 1989, 1990).

Wilkinson and Sherman (1989) interviewed administrators and professors involved in distance education courses to explore the opinions pertaining to student procrastination. The interviews consisted of open-ended questions to gather data in the following four areas: (1) demographic information, (2) perceptions of the distance education program, (3) reasons for student attrition and nonpersistence and (4) definitions of procrastination as a cause of noncompletion of distance courses (Wilkinson \& Sherman, 1989). The participants were from two diverse distance education programs as determined by the researchers. The sample included two professors and two administrators from each distance education program.

Analysis of the interview data revealed four consistent themes: (1) concern about noncompletion, (2) explanations for noncompletion, (3) lack of information about procrastination and (4) lack of time to address procrastination (Wilkinson \& Sherman, 1989). All the participants showed great concern for the high rates of students who do not complete or never begin the course. The rates were estimated to be $30 \%$ to $45 \%$ (Wilkinson \& Sherman, 1989). The data revealed that students who began their course early and paced themselves at a reasonable rate generally completed the course. Students who enroll in distance learning courses of a selfpaced or predetermined pace should have the motivation and self-discipline to establish a timeline or keep up with the timeline prescribed by the professor. Students who lack the motivation or self-discipline tend to procrastinate in the 
distance education courses and therefore, the success of the student is compromised.

Wilkinson and Sherman (1990) conducted another study that surveyed 276 distance education programs. Specifically, program directors, coordinators and faculty of distance education programs were subjects in the study. The purpose of the study was to explore the beliefs and perceptions of procrastination and the effects of procrastination on distance students. The researchers developed two surveys for the study. The Distance Education Program Director Survey was an 80item questionnaire that gathered the following: institutional and program information, student noncompletion and academic procrastination (Wilkinson \& Sherman, 1990). The researchers developed a second survey from the Distance Education Program Director Survey. The Distance Education Faculty Survey included the same items used to collect data pertaining to information on noncompletion and academic procrastination as the Distance Education Program Director Survey.

Directors of each of the 276 distance education programs received a packet that contained one Distance Education Program Director Survey and three Distance Education Faculty Surveys. The directors were asked to participate in the study and select three of the best faculty in distance education to respond to the survey. A return rate of $65 \%$ was determined for the surveys based on the 180 programs that responded to the surveys (Wilkinson \& Sherman, 1990). Some programs refused to participate or returned surveys deemed unusable for the study by the researchers. Therefore, a total of 432 surveys were used in the study. More specifically, 297 
distance faculty and 135 program directors or coordinators responded to the surveys (Wilkinson \& Sherman, 1990).

Results of the surveys indicated that $95 \%$ of the distance educators experienced procrastination in their respective programs (Wilkinson \& Sherman, 1990). In addition, $51.5 \%$ of the respondents reported that $10 \%$ or less of the students withdrew or were dropped from the course for failure to complete course assignments (Wilkinson \& Sherman, 1990). An interesting finding of the study was that approximately $67 \%$ of the distance educators surveyed believed that procrastination was frequently or always caused by unclear priorities and the failure to understand the need for timely action in courses assignments (Wilkinson \& Sherman, 1990). The study supported the earlier findings of the Wilkinson and Sherman (1989) study in that procrastination has a negative impact on distance education course completion rates.

In a similar study, Leasure et al. (2000) studied a group of students who were enrolled in a graduate nursing research course offered both traditionally and via the Internet in the distance education program. The purpose of the study was to examine student outcomes of both delivery modalities. The sample consisted of 66 students who were given the choice to enroll in the traditional course or the Internet course. Identical textbooks, workbooks, activities, exams and software were used in both sections of the course.

A survey was given at the beginning of the course to both sections to investigate the reasons that students selected the traditional and Internet course sections. Survey results showed that students selected the traditional course 
because it allowed a smaller chance to procrastinate (Leasure et al., 2000). More specifically, the students reported that there was increased structure and accountability in the traditional course section. Therefore, students recognized the possibility of procrastination in the Internet section and in order to avoid procrastination, enrolled in the traditional course section to stay on task and complete the course in a timely fashion.

\section{Student Expectations}

The third variable identified by the literature concerning success in distance education was student expectations. Expectations are typically developed before an experience takes place (C. White, 1999). Therefore, students enroll in distance education courses with preconceived ideas about the course. Research has provided evidence that supports the premise that students often enroll in distance courses with unrealistic expectations that eventually lead to nonpersistence. More specifically, first-time or new students enrolled in distance education courses become overwhelmed at the realization that the course is little like it was expected to be (Chyung et al., 1998; Cooper, 2000; Kirtley, 2002; C. White, 1999; Wilkinson \& Sherman, 1989).

In a study by Wilkinson and Sherman (1989), eight distance education administrators and faculty were interviewed primarily to explore the perceptions of procrastination in distance education courses. The participants were from two diverse distance education programs according to Wilkinson and Sherman (1989). Two faculty and two administrators from each program participated in the study. 
The study revealed beliefs of distance educators concerning student expectations in distance courses. Distance educators reported that one reason that students failed to complete a distance education course was the lack of realistic expectations concerning what is required in such courses.

The finding supports the statement by Saba (2000) that many distance learners have not assumed the responsibility for the learning process and therefore, are uncertain as to what is required on behalf of the student to successfully complete a distance course. Most students understand that a distance course is studentcentered and that the student is in charge of the learning process at that point. However, transition from a faculty-centered traditional course to a student-centered distance course can be very difficult for the student. The difficulty experienced by the student can contribute to the noncompletion of the distance course.

Chyung et al. (1998) conducted a study to identify the reasons that students dropout of distance courses and evaluate methods of intervention implemented at the conclusion of the causal analysis stage of the study. The researchers interviewed all the students who had dropped out of a distance education course from the Instructional and Performance Technology Department (ITP) at Boise State University. The number of students interviewed was not stated, however students who dropped out of a distance course from 1989 to 1996 were included in the study.

Results indicated that $42 \%$ of the students cited an unsatisfactory learning environment as the reason for dropout (Chyung et al., 1998). In addition, students who were unsatisfied in the first or second course in the program typically dropped out. Further analysis showed that students who dropped out after the first or second 
course were overwhelmed by the level of knowledge required and amount of information covered the course (Chyung et al., 1998). Students began to question confidence in knowledge, ability to use the software and whether the work submitted was of acceptable quality. The course quickly became something other than originally expected by the student.

The unrealistic expectations of students enrolled in the distance courses can lead the student to become frustrated and discouraged by a new mode of learning (Chyung et al., 1998). Failure to adapt to the new learning modality can be detrimental to the success of the student in distance courses. In most cases, students who fail to understand course requirements and have unrealistic expectations of the course tend to withdraw from the course because of the need for more structure and clarification of expectations as demonstrated in this study.

C. White (1999) conducted a study using students enrolled in foreign language courses offered by a distance education program to determine the expectations and beliefs of the students. The longitudinal study used a phenomenographic approach to observe the perceptions of the learners concerning the self-instructed language approach. The sample consisted of 23 participants enrolled in Japanese and Spanish courses who had always attended traditional courses in foreign language prior to the study.

Five phases of data collection were used throughout the study and included interviews, ranking exercises, questionnaires, scenarios and subject procedures (C. White, 1999). The beginning stages of the study showed that the distance 
courses were very flexible in terms of learning a foreign language, but required students to balance other commitments as well.

Telephone interviews conducted at the mid-term point of the courses revealed that students did not expect that it was the responsibility of the student to make the course "come alive" and work for them (C. White, 1999). It appeared as though some of the students were very surprised at the directive role assumed by the student to function in the course. Also, students stated that they had not expected the degree of uncertainty experienced throughout the course. Students were unsure if assignments were being done correctly, if information was understood as it was intended and whether it was worth the time spent on the course at the mid-term point (C. White, 1999).

The study reiterated that many students enter distance education courses with preconceived notions or ideas of what the course will be like as was evidenced in the study by Chyung et al. (1998). Upon realization that the courses are actually quite different in structure, function and process, students become frustrated and overwhelmed (C. White, 1999). Therefore, unrealistic expectations can have a negative impact on success of the distance learner.

\section{Quality of Instruction}

The literature identifies quality of instruction as the fourth variable that affects student success in distance education courses (Frew \& Weber, 1995; Inman \& Kerwin; 1999; Wilkes \& Burnham, 1991; York et al., 1993). Quality of instruction includes such things as the promptness of course materials received, quality of the course, actual teaching of the course and the role of faculty in distance courses. 
Student satisfaction with the quality of instruction regardless of the specific area can have a positive affect on student success in a distance course.

Course quality. The quality of a distance education course can affect the success of distance learners (Frew \& Weber, 1995; Inman \& Kerwin, 1999; Wilkes \& Burnham, 1991; York et al., 1993). Student satisfaction with the course quality is a predictor for student success. Frew and Weber (1995) surveyed present and past students enrolled in a graduate tourism program. A telephone interview followed the survey to reduce any error associated with unreturned surveys.

The researchers determined that $11 \%$ of the students experienced dissatisfaction with course quality. Specifically, one reason cited by the students was the late arrival of course materials upon matriculation in the course (Frew \& Weber, 1995). Often students expect distance education courses to be a nice complete package that is mailed immediately upon course registration. When course materials do not arrive in a timely manner or something is missing, students become discouraged and motivation levels may decrease as a result (Frew \& Weber, 1995). Results also indicated student dissatisfaction with the lack of information about the course prior to enrollment, overlap of content and inadequate self-assessment activities in the study guide (Frew \& Weber, 1995). Therefore, students experienced unsatisfactory levels of course quality as determined by the results of the study.

In the study by Inman and Kerwin (1999), faculty and students at the University of Kentucky Community College System were surveyed to evaluate the satisfaction of the distance learning experience. The study consisted of 11 faculty teaching the telecourses and 364 students enrolled in telecourses during the fall 
1996 term. Training for the telecourses was provided for faculty and students in an optional orientation session. A survey was sent to the students at the same time as the faculty survey.

Analysis of the data indicated that $45 \%$ of the faculty surveyed stated that the distance course was of low quality (Inman \& Kerwin, 1999). Possible explanations for the low quality may include faculty attitudes towards distance education, individual expectations of faculty and the need to provide additional assistance to students in learning the technology of the course (Inman \& Kerwin, 1999). Perhaps, faculty become frustrated and overwhelmed with the uniqueness of the distance education experience and that affects the perception of course quality. In addition, Inman and Kerwin (1999) discovered that $13 \%$ of the students rated course quality as fair or low. Reasons for student dissatisfaction with course quality could include difficulty with the content or technology.

The study provided evidence that the higher the rating for telecourses materials, the higher the rating for the course quality (Inman \& Kerwin, 1999). In fact, data revealed that $83 \%$ of the students surveyed rated telecourses materials as good or excellent (Inman \& Kerwin, 1999). Another interesting finding of the study was the amount of learning that took place was directly related to the rating of the telecourses materials. Again, high ratings of the telecourses materials corresponded with high ratings for the amount of information learned in the course. The study suggested that the quality of the course relies on the satisfaction with the course materials. It is logical that a distance learner who experiences an unsatisfactory level of course quality may eventually withdraw or fail to complete the course. 
In a study by Wilkes and Burnham (1991), 156 students enrolled in Utah State University's Electronic Distance Education (EDE) system were studied. The purpose of the study was to explore the factors that contribute to learner satisfaction in the EDE system. More specifically, the study examined the relationship between the motivation orientations of the students and the student perceptions of the learning environment that included satisfaction, materials, involvement and extension (Wilkes \& Burnham, 1991). The sample consisted of 83 undergraduate students and 73 graduate students. The study used a comparison group comprised of 85 students enrolled in traditional courses at the university to provide a better understanding of the EDE results (Wilkes \& Burnham, 1991). The comparison group contained 34 undergraduate students and 51 graduate students.

The study used several instruments to collect data. The Education Participation Scale (EPS) by Boshier was used to determine the motivational orientations of the students. The Learning Environment Inventory (LEI) was used to measure the students' perceptions of the learning environment. Subscales from the College and University Classroom Environmental Inventory (CUCEI) were used to measure the involvement and satisfaction levels of the students. Students completed a survey that gathered demographic information such as age, gender, marital status and income. Lastly, data were collected qualitatively by interviews with EDE students to provide information in addition to the quantitative data obtained during the study.

Results of the study demonstrated that a stronger relationship existed between motivational orientations and the satisfaction and involvement of EDE 
courses as compared to traditional courses (Wilkes \& Burnham, 1991). Students in the traditional group exhibited higher scores in satisfaction, involvement and material environment than did the students of the EDE group (Wilkes \& Burnham, 1991). Therefore, the study suggested that EDE students were not as satisfied with the distance course as the traditional students were satisfied with the traditional format.

Furthermore, the EDE group demonstrated a .685 correlation coefficient of the relationship between satisfaction and involvement (Wilkes \& Burnham, 1991). This finding supports the premise that there is a stronger relationship between satisfaction and involvement in the EDE group than the relationship found in the traditional group. Additionally, the data collected from the interviews revealed that there was a perception that EDE courses were inferior to traditional courses (Wilkes \& Burnham, 1991).

Another study investigated the satisfaction of teaching ability in distance education. Many distance education faculty are inexperienced in teaching courses and students can become very discouraged and frustrated with the course (Carr, 2000). A study by York et al. (1993) analyzed records, defined the system and included a longitudinal study to determine the interaction of student characteristics within the institution. The sample consisted of 1722 students enrolled in the fall 1987 term.

Demographic data were collected using the institutional records on file. Retention rates at the institution were determined by whether the student attained a degree or not within five years of entering the institution (York et al., 1993). Interviews were conducted with a group of nonpersisters selected based on whether 
the student returned after the first quarter during the fall 1992 term. The nonpersisters received telephone interviews to identify reasons for nonpersistence. The number one reason that students reported frustration with the distance course was the quality of the teaching (York et al., 1993).

It is important to note that the instructor has a tremendous influence on the students enrolled in distance courses (Wilkes \& Burnham, 1991). Therefore, the students who reported dissatisfaction with the distance course because of the quality of teaching were negatively impacted. Students expect the instructor to provide support and guidance and when unsatisfactory levels of teaching are experienced, the success of the student may be jeopardized.

Role of the faculty. The role of the faculty has changed from the traditional classroom to the distance education arena (Alexander, 1999; Inman \& Kerwin, 1999; Leasure et al., 2000). The literature denotes the change in role as moving from a "sage on the stage" to a "guide on the side" (Alexander, 1999; Leasure et al., 2000). This quote refers to the change in role of the faculty-centered traditional course to that of a student-centered distance course. The faculty is the center of attention and directs the traditional course whereas the student is in control of the learning that takes place in the distance course. The faculty of a distance course primarily functions for assistance and guidance throughout the course.

The role of distance faculty is very different and research has suggested that faculty should receive training to meet the new role and responsibilities of the distance course (Inman \& Kerwin, 1999; Omoregie, 1997; Roberts, 1984). However, very few studies pertaining to role of distance education faculty can be found in the 
literature. Carr (2000) reported that students cited inexperienced teachers as one of the reasons for withdrawal from distance education courses. Perhaps, it is reasonable that the inexperienced faculty have not received training or definition of the new role assumed in teaching a distance course.

Palloff and Pratt (1999) classified the roles of an online instructor into four categories: pedagogical, social, managerial, and technical. It is important to note that the roles are applicable to many types of distance education delivery in addition to online courses. The pedagogical category involves the faculty as a facilitator of the course. Specifically, the faculty provides the guidance and framework for students to examine course materials. In addition, the faculty functions to motivate the student to move forward in the course or to a different level of performance in exploring the material and content of the course. Therefore, it is essential that the faculty provides positive, constructive comments when returning graded assignments and exams or responding to emails and course postings online.

The social role of distance faculty functions to promote socialization in the course. Socialization may include faculty-student communication, chat room discussions and collaborative group projects. This role is primarily associated with communication within the course either between the student and faculty or among students. Many times students feel isolated in distance learning courses and faculty attention to the social needs becomes vital.

The managerial role of distance faculty is the same as that of traditional faculty. Specifically, the managerial role of faculty includes establishing course objectives, policies, syllabi, timelines, and pacing (Palloff \& Pratt, 1999). Faculty 
serve as the decision makers and enforcers of policies and procedures in the courses. The faculty are responsible for grading all assignments and exams as well as determining a final grade for the course.

The technical role of distance faculty requires the faculty to be familiar with the technology used in the course delivery. Familiarity with the technology is required so that the faculty can assist students experiencing technical difficulty with course software. Typically, traditional faculty use power point presentations, videos and overheads to supplement course text whereas; many distance courses use the Internet and software to enhance content delivery. Traditional faculty do not have to teach students how to use the multimedia used in the course, but the distance faculty must do so to assist in student success. Therefore, the distance faculty are different from traditional course faculty as far as the technical role is concerned.

\section{Summary}

Distance education courses have evolved tremendously from the inception of the first correspondence courses in 1840 to the many types of distance delivery modalities found today. The drastic increase in the number of distance education institutions, programs and courses has prompted researchers to investigate attrition rates of such courses and programs. Attrition rates of distance education courses have been found to be higher than that associated with traditional courses (Carr, 2000; Hogan, 1997).

The independent and dependent variables for this study emerged from the comprehensive review of the literature. Numerous studies have been conducted to determine the reasons that students withdraw or fail to complete distance education 
courses. A large amount of the literature dealt with the predictors of a successful distance learner. The literature revealed that students who were successful in distance courses experienced satisfactory levels of faculty-student communication, student time management, student expectations and quality of instruction. 


\section{CHAPTER THREE}

Methods

This study examined the statistical relationship between the dependent variable of student success in distance education courses and the independent variables of faculty-student communication, student time management, student expectations, and quality of instruction as measured by the Distance Education Satisfaction Survey. The review of literature pertaining to distance education attrition rates provided guidance in the development of this investigation. The purpose of this chapter is to describe the research design, the population and sample, instrumentation, data collection, and data analyses that were used in the study. Design

The design of the study was descriptive in nature (Campbell \& Stanley, 1963; Johnson \& Christensen, 2000). Data were collected using a researcher-designed instrument titled the Distance Education Satisfaction Survey. Once the data were collected, respondents were categorized into levels of success by using the selfreported grade in the course. The levels of student success were compared with the self-reported satisfaction levels of faculty-student communication, student time management, student expectations, and quality of instruction.

\section{Population and Sample}

The population consisted of undergraduate students enrolled in the Independent Study (IS) program offered by the School of Distance and Extended Learning at Mountain State University. Mountain State University is a not-for-profit 
private university located in southern West Virginia that offers both undergraduate and graduate programs to more than 3,000 students.

The IS program is one of the distance learning programs offered by Mountain State University. The program enables students to enroll in IS courses any day of the year instead of the prescribed time periods for enrollment found in traditional courses for the spring, summer and fall terms. Students are given six months to complete an IS course from the date of enrollment. Students can request a one-time extension for an additional thirty days on or before the course completion date. The withdrawal policy permits students to withdraw from an IS course on or before the completion date or extended completion date.

The course design focuses on the student-centered approach in that the IS courses are self-paced. More specifically, students set the dates and times for study, assignments and testing. Tests are supervised on campus in the Testing Center or are taken off campus with an approved proctor at another facility. The timeline and withdrawal policy of the IS courses works in conjunction with the course design to offer students flexibility and convenience to complete courses at a distance.

The population for this study consisted of 2372 registrants for Independent Study courses during the summer and fall 2001 terms that completed the courses on or before July 31,2002 . A list of the names and addresses of the IS students was obtained from the Office of the Registrar. Students who registered for more than one IS course appeared on the registration list numerous times. Therefore, the student duplicates were eliminated so that each IS student appeared only one time in the 
population ( $\mathrm{N}=1007)$. Johnson and Christensen (2000) recommended a sample size of 278 for a population of 1000 , which was approximately $28 \%$ of the total population. However, for the design and population of this study, a sample of 500 $(n=500)$ or $50 \%$ was sampled. The enrollment list was imported into SPSS and each student was randomly assigned a number of zero or one. All students who were assigned a number one were included in the sample.

Instrumentation

The Distance Education Satisfaction Survey was a researcher-designed instrument developed from the literature reviewed for this study (see Appendix A). The one-page survey consisted of 17 items with forced choice statements and Likert scale responses as recommended by Babbie (1990), Johnson and Christensen (2000) and Fowler (2002). Participants were asked to read each statement carefully and circle the appropriate response to the statement. Four questions were designed to measure each independent variable and one question was designed to report the level of student success.

Each question developed for the survey was based on the literature regarding faculty-student communication, student time management, student expectations, and quality of instruction in distance education courses. Specific reasons cited for satisfactory faculty-student communication included adequate contact initiated by the student and faculty (Morgan \& Tam, 1999), timely faculty response time to phone calls or emails and good turnaround time in grading assignments and exams (Garland, 1993b; Minich, 1996), and the availability of the faculty during the designated times in the syllabus (Garland, 1993b; Inman \& Kerwin, 1999). The 
reasons cited for satisfactory faculty-student communication were included in the survey to determine what relationship, if any, existed between faculty-student communication and the level of student success in distance education courses.

The literature indicated that students who have adequate time management skills and do not tend to procrastinate persist in distance courses. These students are able to balance an education, family and career (Garland, 1993b; Herrmann, 1988; Minich, 1996; Morgan \& Tam, 1999; Towles, Ellis \& Spencer, 1993), have adequate time management skills (Garland, 1993b; Morgan \& Tam, 1999), and pace themselves well and do not procrastinate (Leasure, Davis \& Thievon, 2000; Wilkinson \& Sherman, 1989; 1990). Therefore, questions on the survey pertaining to student time management and procrastination were included to determine what relationship, if any, existed between student time management and level of student success in distance education courses.

Students who held realistic expectations about the format of the course, amount of content, and self-directive nature of distance courses were successful in distance courses. Students were not surprised by the amount and difficulty of content (C. White, 1999), self-directed nature of the course (C. White, 1999; Wilkinson \& Sherman, 1989), required knowledge and learning (Chyung, Winiecki \& Fenner, 1998; C. White, 1999), and the quality of the work submitted for grading (Chyung et al., 1998; C. White, 1999). Therefore, the literature supported the inclusion of these domains on the survey to determine what relationship, if any, existed between student expectations and level of student success in distance education courses. 
Students who experience satisfactory levels of the quality of instruction tend to complete the distance courses. Students cited satisfaction in the promptness of materials received (Frew \& Weber, 1995), high course quality (Inman \& Kerwin, 1999; Wilkes \& Burnham, 1991) course difficulty (Inman \& Kerwin, 1999), and good support and guidance by faculty (Wilkes \& Burnham, 1991; York, Bollar \& Schoob, 1993). The survey questions designed for quality of instruction included these domains to determine what relationship, if any, existed between quality of instruction and level of student success in distance education courses.

The survey was designed to be self-administered to measure student perceptions of faculty-student communication, student time management, student expectations, and quality of instruction. The researcher developed the survey and therefore, the validity of the survey was compromised. Johnson and Christensen (2000) noted that instruments developed by researchers are limited because the ability to measure what the instrument is intended to measure and obtain similar results under similar conditions is questionable. Therefore, a panel of 21 graduate students familiar with distance education was used to review the survey to determine the average length of time to complete the survey, readability of the items and to provide face validity for the instrument (Babbie, 1990; Fowler, 2002; Johnson \& Christensen, 2000). The instrument was modified to reflect changes based upon the recommendations of the panel. The average length of time to complete the survey was five minutes.

\section{Data Collection}

Permission was obtained from the West Virginia University and Mountain 
State University Institutional Review Boards for the Protection of Human Subjects prior to beginning this study (see Appendix B). The Mountain State University Office of the Registrar provided an enrollment list for the summer and fall 2001 terms.

The study used self-reported questionnaire survey procedures to collect the data (Kerlinger, 1986). A packet was sent to each student in the sample during August 2002. The packet included a cover letter from the researcher that explained the study (see Appendix C), a copy of the Distance Student Satisfaction Survey (see Appendix A), and a preaddressed, stamped reply envelope. The cover letter explained the focus of the study, conveyed that participation is voluntary, guaranteed anonymity for participants, stated the student did not have to answer every question, and that the study had been approved by the Institutional Review Boards for the Protection of Human Subjects at West Virginia University and Mountain State University.

The recipients of the survey were asked to complete the survey and return it to the researcher within two weeks. A follow-up letter (Appendix D) and a second copy of the survey were sent three weeks after the original mailing date to reduce the level of nonresponse. Johnson and Christensen (2000) and Kerlinger (1986) recommended a return rate of $50 \%$ plus one to analyze the data. Therefore, a minimum of 251 surveys should be returned before data analysis is performed.

\section{Data Analysis}

Once the completed surveys were received, data analysis was conducted to determine what relationship, if any, existed between the level of student success and faculty-student communication, student time management, student expectations, 
and quality of instruction. Data analyses included the use of frequencies and Analysis of Variance (ANOVA). Post hoc analyses were conducted as needed. An alpha level of 0.05 was used to determine the level of significance for this study.

\section{Summary}

The methods presented in this chapter were designed to determine if faculty-student communication, student time management, student expectations, and quality of instruction had a statistically significant relationship with the level of student success in a distance course. A sample of 500 students enrolled in IS courses at Mountain State University who were selected randomly were surveyed. Data analyses were performed using the 0.05 alpha level to answer the research questions posed in the study. 


\section{CHAPTER FOUR}

Presentation and Analyses of the Data

The purpose of this chapter is to present the data collected from undergraduate students enrolled in Independent Study (IS) courses at Mountain State University (MSU) during the summer and fall 2001 terms. Data analyses were performed to determine if there were statistically significant differences within the independent variables of faculty-student communication, student time management, student expectations and quality of instruction based on the dependent variable of level of student success. Conclusions related to student success in the IS courses were based on the findings of the study.

The analyses and presentation of the data is organized to follow the outline of the research questions presented in Chapter One. The data were collected by the distribution of the researcher-designed survey instrument (The Distance Education Satisfaction Survey, see Appendix A) to a random sample of students enrolled in IS courses at MSU during the summer and fall 2001 terms. The data collected from the survey were coded and analyzed using the SPSS, version 11.0. Coding of the data represented the student responses on the survey instrument. This chapter includes the presentation of descriptive data, major findings, ancillary findings and chapter summary.

\section{Population and Sample}

The Distance Education Student Satisfaction survey was mailed to the random sample $(n=500)$ of students who were enrolled in IS courses at MSU during the summer and fall 2001 terms. A total of 258 surveys were returned (52\% return 
rate), however 13 of the surveys were determined to be unusable. The data analyzed in the study included survey responses from 245 students (49\% return rate).

The MSU Office of the Registrar provided an enrollment list for IS courses for the summer and fall 2001 terms. The enrollment list consisted of the universityassigned student identification number, student name and mailing address. The total population for this study included 2372 registrants who enrolled in IS courses during the summer and fall 2001 terms. Duplicated student enrollments were eliminated to ensure that each student appeared only one time in the population $(N=1007)$.

The enrollment list was imported into SPSS to create a true random sample. SPSS was used to randomly assign a number of zero or one to each student identification number in the population. The recommended sample size for a population of 1000 was 278 , which was approximately $28 \%$ of the population (Johnson \& Christensen, 2000). All 500 students who were randomly assigned a number of one were included in the sample to maximize representation of the population. The 258 returned surveys constituted an overall response rate of $52 \%$ for the sample and the 245 usable surveys represented a $49 \%$ response rate for the sample.

\section{Statistical Methods}

Analyses of Variance (ANOVA) were used to conduct data analyses to determine if a statistically significant difference existed within the independent variables of faculty-student communication, student time management, student expectations, and quality of instruction based upon the dependent variable of level of 
student success. Descriptive statistics were used for the level of student success and ancillary data.

ANOVAs were performed on the four survey questions representative of each independent variable to determine what difference, if any, existed in each category within each independent variable based upon the level of student success. The purpose of the ANOVA is to provide evidence of a relationship between two or more variables without defining strength or intensity (Johnson \& Christensen, 2000).

\section{Descriptive Data}

The literature revealed that students who are successful in distance education courses experience satisfactory levels of faculty-student communication, possess adequate time management skills, hold realistic expectations, and experience satisfactory levels of quality of instruction. This study defined the level of student success as the grade earned in the IS course as reported on the survey instrument. The data were analyzed to determine the frequency of grades reported on the survey instrument. Table 1 shows that $95.9 \%$ of the survey respondents reported that a letter grade of $A, B$ or $C$ was earned in the course. Table 1 shows that $4 \%$ of the respondents reported that a letter grade of D, F, or W was earned in the course. Nearly all the respondents successfully completed the distance course. 
Table 1

Frequency of Level of Student Success

\begin{tabular}{ccc}
\hline Level of Student Success & Frequency & Percent \\
\hline A & 116 & 47.3 \\
B & 87 & 35.5 \\
C & 32 & 13.1 \\
D & 3 & 1.2 \\
F & 4 & 1.6 \\
W & 3 & 1.2 \\
Total & 245 & 99.9 \\
\hline
\end{tabular}

The Distance Education Satisfaction Survey instrument included two questions to obtain demographic data to provide possible ancillary findings of the study. The demographic survey questions required students to provide their sex and age. The findings regarding the sex and age data are descriptive in nature. Analysis of the data found the average age of the 245 survey respondents to be 31 . In addition, the findings revealed that $74.7 \%$ of the survey respondents were female and $24.1 \%$ were male. These data are relatively consistent with MSU institutional statistics for the 2001 calendar year. The average age of the undergraduate student was 26 and the student body is comprised of approximately $65 \%$ females and $35 \%$ males. 


\section{Major Findings}

The study was designed to answer four research questions pertaining to student perceptions of faculty-student communication, student time management, student expectations, and quality of instruction as related to student success in distance education courses. The data for each research question were collected from the student responses on the Distance Education Satisfaction Survey. Research Question One

What is the relationship, if any, between faculty-student communication and the level of student success in distance education courses? To answer the research question, data were analyzed using survey questions 1-4 to determine if a relationship existed between faculty-student communication and the level of student success. The data were analyzed using an ANOVA that represented a summative score for faculty-student communication that was comprised of the responses on each of the four survey questions within the category. Table 2 shows that there was a statistically significant difference within faculty-student communication based on the level of student success $\left(F=2.989^{*}\right.$ at $\left.p<.05\right)$. Based upon the information from the survey data, there appears to be a statistically significant relationship between the independent variable of faculty-student communication and the dependent variable of level of student success in this question. 
Table 2

Summary of One-Way Analysis of Variance for Faculty-Student Communication (Survey Questions 1-4)

\begin{tabular}{lcrrr}
\hline$\underline{\text { Source }}$ & $\underline{\mathrm{df}}$ & $\underline{\mathrm{F}}$ & $\underline{\mathrm{SS}}$ & $\underline{\mathrm{MS}}$ \\
\hline Communication & 5 & $2.989^{*}$ & 66.222 & 13.244 \\
Within groups & 239 & & 1059.190 & 4.432 \\
Total & 244 & & 1125.412 & \\
\hline
\end{tabular}

${ }^{*} p<.05$.

Research Question Two

What is the relationship, if any, between student time management and the level of student success in distance education courses? To answer the research question, data were analyzed using survey questions $5-8$ to determine if a difference existed within student time management based on the level of student success. The data were analyzed using an ANOVA that represented a summative score for student time management that was comprised of the responses on each of the four survey questions within the category. Table 3 shows that there was a statistically significant difference within student time management based on the level of student success $\left(F=6.064^{*}\right.$ at $\left.p<.05\right)$. Based upon the information from the survey data, there appears to be a statistically significant relationship between the independent 
variable of student time management and the dependent variable of level of student success in this question.

Table 3

Summary of One-Way Analysis of Variance for Student Time Management (Survey Questions 5-8)

\begin{tabular}{lcrrr}
\hline \multicolumn{1}{c}{ Source } & $\underline{\mathrm{df}}$ & $\underline{\mathrm{F}}$ & $\underline{\mathrm{SS}}$ & $\underline{\mathrm{MS}}$ \\
\hline Time Management & 5 & $6.064^{*}$ & 125.625 & 25.125 \\
Within groups & 239 & & 990.196 & 4.143 \\
Total & 244 & & 1115.820 & \\
\hline
\end{tabular}

${ }^{*} p<.05$.

Research Question Three

What is the relationship, if any, between student expectations and the level of student success in distance education courses? To answer the research question, data were analyzed using survey questions $9-12$ to determine if a relationship existed within student expectations based on the level of student success. The data were analyzed using an ANOVA that represented a summative score for student expectations that consisted of the responses on each of the four survey questions within the category. Table 4 shows that there was a statistically significant difference within student expectations based on the level of student success $\left(F=2.816^{*}\right.$ at $\mathrm{p}<.05)$. Based upon the information from the survey data, there appears to be a 
statistically significant relationship between the independent variable of student expectations and the dependent variable of level of student success in this question. Table 4

Summary of One-Way Analysis of Variance for Student Expectations (Survey Questions 9-12)

\begin{tabular}{lcccc}
\hline$\underline{\text { Source }}$ & $\underline{\mathrm{df}}$ & $\underline{\mathrm{F}}$ & $\underline{\mathrm{SS}}$ & $\underline{\mathrm{MS}}$ \\
\hline Expectations & 5 & $2.816^{*}$ & 38.192 & 7.638 \\
Within groups & 216 & & 586.006 & 2.713 \\
Total & 221 & & 624.198 & \\
\hline
\end{tabular}

${ }^{*} p<.05$.

Research Question Four

What is the relationship, if any, between the quality of instruction and the level of student success in distance education courses? To answer the research question, data were analyzed using survey questions $13-16$ to determine if a relationship existed within the quality of instruction based on the level of student success. The data were analyzed using an ANOVA that represented a summative score for the quality of instruction that consisted of the responses on each of the four survey questions within the category. Table 5 shows that there was a statistically significant difference within the quality of instruction based on the level of student success $\left(F=6.524^{*}\right.$ at $\left.p<.05\right)$. Based upon the information from the survey data, there 
appears to be a statistically significant relationship between the independent variable of quality of instruction and the dependent variable of level of student success in this question.

Table 5

Summary of One-Way Analysis of Variance for Quality of Instruction (Survey Questions 13-16)

\begin{tabular}{lcccc}
\hline \multicolumn{1}{c}{ Source } & $\underline{\mathrm{df}}$ & $\underline{\mathrm{F}}$ & $\underline{\mathrm{SS}}$ & $\underline{\mathrm{MS}}$ \\
\hline Quality of Instruction & 5 & $6.524^{*}$ & 114.858 & 22.972 \\
Within groups & 239 & & 841.566 & 3.521 \\
Total & 244 & & 956.424 & \\
\hline${ }^{*} \mathrm{p}<.05$. & & & & \\
\end{tabular}

\section{Ancillary Findings}

An ANOVA was conducted on each individual survey question within each category representing the independent variables of faculty-student communication, student time management, student expectations, and quality of instruction. Findings of the ANOVAs provided the ancillary findings for this study. Faculty-Student Communication

ANOVAs were performed on each of the four survey questions representing the category of faculty-student communication. Results indicated that only one of the four questions for this category exhibited statistical significance. Survey question 
four required students to respond to the statement "The turnaround time for grades on assignments and exams was" by selecting one of the following responses:

excellent, good, fair or poor. The ANOVA performed on survey question four found a statistically significant difference existed within turnaround time for grades on assignments and exams based on the level of student success $\left(F=3.089^{*}\right.$ at $\left.p<.05\right)$. Survey questions one, two and three did not demonstrate statistical significance.

\section{Student Time Management}

ANOVAs were performed on each of the four survey questions representing the category of student time management. Results indicated that all survey questions for this category exhibited statistical significance. Survey question five required students to respond to the statement "My time management skills in this course were" by selecting one of the following responses: excellent, good, fair or poor. The ANOVA performed on survey question five found a statistically significant difference existed within student time management skills based on the level of student success $\left(F=4.446^{*}\right.$ at $\left.p<.05\right)$. Survey question six required students to respond to the statement "I found the challenge of balancing an education, family and/or career" by selecting one of the following responses: easy, challenging, difficult or impossible. The ANOVA conducted on survey question six found a statistically significant difference existed within the ability to balance multiple roles based on the level of student success $\left(F=10.584^{*}\right.$ at $\left.p<.05\right)$.

Survey question seven required students to respond to the statement "My ability to pace myself in the course was" by choosing one of the following responses: excellent, good, fair or poor. The ANOVA performed on survey question seven 
revealed that a statistically significant difference existed within pacing ability based on the level of student success $\left(F=4.098^{*}\right.$ at $\left.p<.05\right)$. The last survey question in the category of student time management required students to respond to the statement "Once I registered for the course, I began working on assignments or exams within" by selecting one of the following responses: $1-4$ weeks, $2-3$ months, $4-5$ months or 6 months. Survey question eight exhibited a statistically significant difference within the initial time period the student began the course based on the level of student success $\left(F=3.606^{*}\right.$ at $\left.p<.05\right)$.

\section{Student Expectations}

ANOVAs were performed on each of the four survey questions representing the category of student expectations. Results indicated that three survey questions for this category showed statistical significance. Survey question nine required students to respond to the statement "I found the amount of content, assignments and exams in the course was" by selecting one of the following responses: greater than I expected, about what I expected or less than I expected. The ANOVA performed on survey question nine found a statistically significant difference existed within the expectations of the amount of content, assignments and exams based on the level of student success $\left(F=3.963^{*}\right.$ at $\left.p<.05\right)$.

Survey question ten required students to respond to the statement "The self-directed nature of this course was" by selecting one of the following responses: greater than I expected, about what I expected, less than I expected. The ANOVA conducted on survey question ten found a statistically significant difference existed within the expectations of the self-directed nature of the course based on the level of 
student success $\left(F=4.990^{\star}\right.$ at $\left.p<.05\right)$. Survey question twelve required students to respond to the statement "The quality of my work submitted for grading was" by selecting one of the following responses: greater than I expected, about what I expected or less than I expected. The ANOVA performed on survey question twelve revealed that a statistically significant difference existed within the student expectations of the quality of work submitted for grading based on the level of student success $\left(F=2.902^{*}\right.$ at $\left.p<.05\right)$. Survey question eleven did not exhibit statistical significance.

\section{Quality of Instruction}

ANOVAs were performed on each of the four survey questions representing the category of quality of instruction. Results indicated that two survey questions for this category demonstrated statistical significance. Survey question fourteen required students to respond to the statement "Compared to a traditional course, I found the quality of my Independent Study course to be" by choosing one of the following responses: excellent, good, fair or poor. The ANOVA performed on survey question fourteen found a statistically significant difference existed within the quality of a distance courses as compared to traditional course based on the level of student success $\left(F=4.763^{*}\right.$ at $\left.p<.05\right)$.

Survey question sixteen required students to respond to the statement "The support and guidance provided by my instructor was" by selecting one of the following responses: excellent, good, fair or poor. The ANOVA conducted on survey question sixteen found a statistically significant difference existed within the support and 
guidance provided by the instructor based on the level of student success $\left(F=5.350^{*}\right.$ at $p<.05)$. Survey questions thirteen and fifteen did not show statistical significance.

\section{Summary}

Data analyses were conducted using ANOVAs. Descriptive data included the frequencies of each grade reported on the survey instrument. The grade frequencies represented the level of student success in the distance course. Analysis of the level of student success as reported on the survey instrument indicated that $95 \%$ of the students reported earning a grade of $A, B$ or $C$ in the course. Four percent of students reported a grade of $\mathrm{D}, \mathrm{F}$ or $\mathrm{W}$ in the course.

ANOVAs were performed on each independent variable (faculty-student communication, student time management, student expectations, and quality of instruction) to determine what relationship, if any, existed based on the level of student success. The ANOVAs performed on the data demonstrated a statistically significant difference was found within each independent variable based on the level of student success.

Ancillary findings were based upon the ANOVAs conducted on each survey question within each independent variable category. The ANOVAs provided evidence that several survey questions within each category of faculty-student communication, student time management, student expectations, and quality of instruction exhibited statistically significant differences within specific subcategories of the independent variables based on the level of student success.

Demographic data collected on the survey were analyzed to provide ancillary findings for the study. The data analyses indicated that the average age for the 
undergraduate sample was 31 . Student respondents were predominantly female with a representation of $74.7 \%$ while $24.1 \%$ of the student respondents were male. 


\section{CHAPTER FIVE}

Summary, Conclusions, and Recommendations

This chapter is will provide the purpose of the study, a summary of the procedures used in the study, a summary of findings and conclusions. Implications of the study and recommendations for further research are included in this chapter.

\section{Purpose of Study}

The intent of the study was to identify predictors of student success in distance education courses. This study examined the relationship between the independent variables of faculty-student communication, student time management, student expectations, and quality of instruction and the dependent variable of level of student success in distance education courses. The following research questions guided the analysis of data:

Q1. What is the relationship, if any, between faculty-student communication and the level of student success in distance education courses?

Q2. What is the relationship, if any, between student time management and the level of student success in distance education courses?

Q3. What is the relationship, if any, between student expectations and the level of student success in distance education courses?

Q4. What is the relationship, if any, between quality of instruction and the level of student success in distance education courses?

\section{Summary of Procedures}

A descriptive research design was used in this study to examine the relationship between faculty-student communication, student time management, 
student expectations, and quality of instruction and the level of student success (Campbell \& Stanley, 1963; Johnson \& Christensen, 2000). The independent variables selected for this study were based on the literature that indicated that faculty-student communication, student time management, student expectations, and quality of instruction are contributing factors to distance education attrition rates (Chyung, Winiecki \& Fenner, 1998; Cooper, 2000; Frew \& Weber, 1995; Hogan, 1997; Minich, 1996; Saba, 2000; Wilkinson \& Sherman, 1989).

\section{Population and Sample}

The population of this study included students enrolled in Independent Study (IS) courses at Mountain State University (MSU) during the summer and fall 2001 terms $(\mathrm{N}=2372)$. Students who enrolled in more than one course during those terms appeared within the enrollment list more than one time. Therefore, duplicates were removed from the enrollment list to ensure that each student only appeared on the population one time. The resulting population for this study was 1007 students. A random sample of 500 students was selected for the study.

A total of 258 surveys were returned representing a response rate of $52 \%$. However, 13 of the surveys were unusable and 245 surveys were used in the data analyses, providing a response rate of $49 \%$. The data collected from the survey responses were coded and imported into SPSS to provide frequency tables and Analysis of Variance (ANOVA) tables. An alpha level of .05 was used to determine statistical significance. 


\section{Instrument}

The Distance Education Satisfaction Survey was developed by the researcher based on a comprehensive review of the literature. Four questions were developed to measure each independent variable (faculty-student communication, student time management, student expectations, and quality of instruction) and one question was designed to collect information regarding the dependent variable of level of student success.

\section{Summary of Findings}

The relationship between faculty-student communication, student time management, student expectations, and quality of instruction and the level of student success was examined using an Analysis of Variance (ANOVA). The findings of this study provided evidence that a statistically significant difference does exist within faculty-student communication, student time management, student expectations, and the quality of instruction based on the level of student success.

\section{Major Findings}

The research questions in this study examined what relationship, if any, existed between faculty-student communication, student time management, student expectations, and quality of instruction and the level of student success in distance courses. ANOVAs were performed on the summative score representing the four survey questions for each independent variable. Data analyses showed that a statistically significant difference existed within faculty-student communication, student time management, student expectations, and quality of instruction based upon the level of student success. 


\section{Ancillary Data}

Ancillary data were collected from the Distance Education Satisfaction Survey. ANOVAs were performed on each survey question within an independent variable category to determine the presence of statistical significance. Overall, 10 survey questions out of 16 representing all four independent variables exhibited a statistically significant difference based on the dependent variable.

Of the four survey questions that measured faculty-student communication, only one question exhibited statistical significance. The question that examined student perceptions of the turnaround time for grades on assignments and exams showed a statistically significant difference based on the level of student success.

Each of he four survey questions that represented student time management provided evidence of statistical significance. The survey questions measured the student's time management skills, ability to balance an education, family and career, pacing ability, and tendency to procrastinate on beginning the course assignments and exams. A statistically significant difference was found within each category of student time management based upon the level of student success.

Three of the four survey questions that measured student expectations exhibited statistical significance. The survey questions measured the student's expectations of the amount of content, assignments, and exams, self-directed course format, and quality of work submitted for grading. The analyses of data indicated that a statistically significant difference existed within each category of student expectations based upon the level of student success. 
Two survey questions that measured the quality of instruction found statistical significance. The survey questions examined the student's perception of the quality of a distance education course as compared to a traditional course and the support and guidance provided by the instructor. Both survey questions demonstrated a statistically significant difference within each category of quality of instruction based on the level of student success.

\section{Conclusions}

ANOVAs were performed on the summative score of each of the four questions representing the independent variables of faculty-student communication, student time management, student expectations, and quality of instruction. In addition, ANOVAs were also performed on each question within each category. The data analyses resulted in the following conclusions pertaining to the research questions presented in Chapter One.

Research Question One

The analyses of summative scores for the four survey questions that represented the category of faculty-student communication indicated that statistical significance existed between faculty-student communication and the level of student success. Studies have indicated that faculty-student communication is a vital key in the success of distance learners. More specifically, research contends that students should experience frequent communication with the faculty and the communication should be of an acceptable quality to the student (Alexander, 1999; Bean, 1982; Prather \& Hand, 1986; Terenzini \& Pascarella, 1980; Saba, 2000). The data collected in this study confirm the observation that students who experience 
satisfactory levels of frequent faculty-student communication tend to be more successful in distance education courses.

Analyses of the data obtained from each individual survey question representing the category of faculty-student communication revealed statistical significance between the turnaround time in grading assignments and exams and the level of student success. Previous research states that quick feedback concerning grades is an effective management strategy that can promote student motivation and interest in continuing on in the course (Garland, 1993b; Minich, 1996; Saba, 2000). The findings of this study concur with the premise that successful students experience satisfactory turnaround times on the grading of assignments and exams.

Data analyses revealed that there was no statistical significance between the number of times the student attempted to contact the instructor, the instructor response time to the contact, and the availability of the instructor during the times listed in the syllabus and the level of student success. Therefore, the data did not support the previous research that indicates distance learners want a quick response from faculty following initiation of contact (Alexander, 1999; Saba, 2000) and expect the faculty to be available during the hours listed in the syllabus (Garland, 1993b; Inman \& Kerwin, 1999). The population of students for this study consisted of nontraditional students who were more mature, patient, experienced, and knowledgeable, contributing to the finding of no significance.

Faculty-student communication has been identified as a contributing factor to the success of distance learners (Alexander, 1999; Bean, 1982; Prather \& Hand, 
1986; Terenzini \& Pascarella, 1980; Saba, 2000). The findings of this study provided evidence that there is statistical significance between faculty-student communication and the level of student success. Based on the findings, it is important that colleges and universities focus on promoting satisfactory faculty-student communication in order to decrease student attrition.

\section{Research Question Two}

The analyses of summative scores for the four survey questions that represented the category of student time management indicated that statistical significance existed between student time management and the level of student success. The statistical significance supports previous research that demonstrates successful students have the ability to balance multiple roles and avoid procrastination in distance courses (Garland, 1993a, 1993b; Guernsey, 1998; Janssen \& Carton, 1999; Jegede et al., 1999; Leasure et al., 2000; Minich, 1996; Morgan \& Tam, 1999; Prather \& Hand, 1986; Saba, 2000; Taplin \& Jegede, 2001; Wang \& Newlin, 2000; Wilkinson \& Sherman, 1989, 1990). The findings of this study suggest that successful students are able to prioritize family, career and educational obligations and maintain a balance without one particular entity suffering.

Analyses of each individual survey question representing the category of student time management provided evidence of statistical significance between the student's time management skills, ability to balance multiple roles, pacing ability, and tendency to procrastinate and the level of student success. The findings of this study support the literature that indicates successful students possess adequate time management skills that are necessary to balance the multiple roles of a busy lifestyle 
(Garland, 1993b; Herrmann, 1988; Minich, 1996; Morgan \& Tam, 1999; Towles et al., 1993). For a student to be successful in a distance course, the student must be able to set aside specific blocks of time for studying outside the obligations of family and career.

Time management skills are directly associated with the student's ability to pace themselves in a distance course. The findings of this study confirm the previous research in that students who began the course early and paced themselves at a reasonable rate were successful in the course (Wilkinson \& Sherman, 1989). The student's pacing ability is essential in preventing procrastination in the distance course. The literature states that successful students begin working on assignments and exams early in the distance course (Leasure et al., 2000; Wilkinson \& Sherman, 1989; 1990). Beginning to work through course materials, assignments and exams early on in a distance course enables the successful student to avoid procrastination. The successful distance learner possesses the time management skills necessary to work within a timeline of study to avoid procrastination, which negatively impacts student success.

Student time management was a variable identified by the literature as a contributing factor to student success in distance education courses. Based on the findings of this study, distance education providers need to be aware of the student time management skills required to be successful in distance courses. Colleges and universities could provide assistance in sharpening time management skills for those students who lack adequate skills to be successful in a distance course. Distance education provider awareness of the importance in student time management skills 
and willingness to provide assistance in acquiring adequate skills for success in distance courses can provide a "win-win" situation for the success of the student and decrease in attrition within the institution.

\section{Research Question Three}

The analyses of summative scores for the four survey questions that represented the category of student expectations indicated that statistical significance existed between student expectations and the level of student success. Studies have demonstrated that successful students hold realistic expectations about distance courses (Chyung et al., 1998; Cooper, 2000; Kirtley, 2002; C. White, 1999; Wilkinson \& Sherman, 1989). The data in this study confirm the observation that students who hold realistic expectations tend to be more successful in distance education courses. Therefore, successful students have a reasonable understanding of what is involved in taking a distance education course.

Analyses of each individual survey question representing the category of student expectations provided evidence of statistical significance between the amount of content, assignments and exams in the course, self-directed nature of the course, and quality of the work submitted for grading and the level of student success. This study confirm previous research that demonstrated successful students expected the amount of content, assignments and exams in the course and were not surprised by the course in this respect (C. White, 1999).

The literature demonstrates that successful students are not surprised by the self-directed nature of the distance course and expect to assume a student-centered role in the course (C. White, 1999; Wilkinson \& Sherman, 1989). 
Distance learners expect that distance courses are student-centered and a proactive and directive role is assumed by the student to complete the course. The findings of this study confirm previous studies in that a relationship exists between realistic expectations of the self-directed nature of a distance course and the level of student success. Therefore, successful students expect to assume a self-directed role in distance courses.

The findings of this study provided evidence of support for the literature that indicates successful students expect to have confidence in the quality of work submitted for grading (Chyung et al., 1998; C. White, 1999). More specifically, students who lack confidence in the quality of work submitted for grading quickly become frustrated with the distance course because the course becomes something other than expected. In contrast, students who are confident in the quality of work submitted are satisfied with the course and hold realistic expectations that contribute to the success of the student.

Data analyses did not reflect statistical significance between the student's ability to learn and understand content presented in the course and the level of student success. This finding contradicted the literature that observed successful students possess confidence in the ability to learn and understand the content presented in the course (Chyung et al., 1998). The student's ability to learn and understand content is closely associated with the self-directed nature of the distance course and a lack of confidence in the ability to assume this role and accept responsibility for one's learning may become overwhelming and result in unrealistic expectations for the course (Chyung et al., 1998; C. White, 1999). Nontraditional 
students are more experienced, knowledgeable, and assume the self-directed role more easily than younger students, which may explain why no significance was found.

Student expectations were identified by the literature as a contributing factor to the success of distance students (Chyung et al., 1988; Cooper, 2000; Kirtley, 2002; C. White, 1999; Wilkinson \& Sherman; 1989). The findings of this study support the previous research that found successful students have realistic expectations in distance education courses. Distance education providers need to recognize the importance of student expectations in distance courses. Colleges and universities need to provide accurate information that reflects the true nature of distance courses offered at the institution. Descriptions of distance courses and programs should be available to students for review prior to enrollment in a course. It is essential that students obtain accurate information about the course so that realistic expectations are developed prior to enrollment.

\section{Research Question Four}

The analyses of summative scores for the four survey questions that represented the category of quality of instruction demonstrated that statistical significance existed between the quality of instruction and the level of student success. The data analyses support the previous research that demonstrates successful students experience satisfactory levels of quality of instruction (Frew \& Weber, 1995; Inman \& Kerwin, 1999; Wilkes \& Burnham, 1991, York et al., 1993). Quality of instruction includes such things as promptness in the arrival of course 
materials, quality of the course, course instruction, and the role of faculty in distance courses.

Analyses of each individual survey question representing the category of quality of instruction found statistical significance between the quality of a distance course as compared to a traditional course and support and guidance and the level of student success. The findings of this study provide support for the literature that indicates student satisfaction with the course quality is a predictor for success in distance education (Frew \& Weber, 1995; Inman \& Kerwin, 1999; Wilkes \& Burnham, 1991; York et al., 1993). Students who felt that distance courses were equal to or superior in quality as compared to traditional courses tended to be successful in the course.

The literature states that students who are satisfied with the role of the faculty tend to be successful in distance courses (Wilkes \& Burnham, 1991; York et al., 1993). The role of the faculty in distance courses is to provide the support and guidance necessary for a student to succeed while the student assumes a self-directed teaching role in the course (Alexander, 1999; Leasure et al., 2000; Palloff \& Pratt, 1999). The findings confirm prior studies in that the students who had satisfactory experiences with the support and guidance of the faculty were successful in the course (Alexander, 1999; Leasure et al., 2000; Palloff \& Pratt, 1999).

Statistical significance was not found between the promptness of course materials and difficulty of the content and the level of student success. The findings of this study did not support the literature that indicates that satisfactory receipt of 
course materials in a reasonable time is a predictor of student success (Frew \& Weber, 1995). The literature revealed that students who received the course materials in a reasonable period of time upon course registration, however this study did not confirm prior research. The findings of this study did not provide support for the literature that argues successful students experience satisfactory levels of content difficulty (Inman \& Kerwin, 1999). Students who find the level of content difficulty reasonable tend to be successful in distance courses, however that was not confirmed by this study. The nontraditional students are more patient in receiving materials and expect distance courses to be challenging based upon life experiences and knowledge, possible contributing to the finding of no significance.

The quality of instruction was identified by the literature as a contributing factor to the success of distance students (Frew \& Weber, 1995; Inman \& Kerwin, 1999; Wilkes \& Burnham, 1991; York, Bollar \& Schoob, 1993). The findings of this study provided evidence that the quality of instruction is a predictor of success for distance students. Distance education providers need to recognize the importance of quality of instruction in the success of distance students. More specifically, colleges and universities should focus on course quality and role of the faculty. Institutions of higher education should ensure that the quality of distance courses is comparable to traditional courses offered by the institution. Colleges and universities could provide training to distance education faculty to provide assistance in the transition from a traditional classroom to a distance course. 


\section{Implications}

The findings of this study provide many implications for School of Extended and Distance Learning (SEDL) at Mountain State University (MSU). This study demonstrated that faculty-student communication, student time management, student expectations, and quality of instruction, as related to level of student success, are predictors of student success in Independent Study (IS) courses. Therefore, it is essential that Mountain State University examine the findings of this study to identify areas of strengths to provide reinforcement and challenges to provide methods of intervention targeted to reduce attrition in Independent Study courses.

The findings of this study enable administrators in the SEDL to create a profile of the successful student. The profile can be used in conjunction with the findings of the study to provide methods of reinforcement and intervention to retain students in the IS program. The importance of faculty-student communication, student time management, student expectations and quality of instruction in relation to student success was confirmed in this study. Therefore, SEDL administrators should examine the possibility of providing some type of in-service training to faculty teaching IS courses as well as other distance courses. The in-service training should include information about the importance of responding to student-initiated contact, mediums of communication available for use in the course and the faculty role in a distance course. Such training would prove beneficial for distance faculty because it focuses on the things faculty can do to promote satisfactory experiences with the student and contribute to the success of the student. 
SEDL administrators should examine the possibility of establishing an orientation session for all students taking a distance course for the first time. An analysis of the geographical regions could be performed to determine the location of various orientation sessions to accommodate students within a reasonable distance from campus. Students that are located in other states and countries could participate in an online orientation session. The orientation sessions could be held be held each month to accommodate ongoing distance course registration,

The orientation session could focus on the importance of student time management skills and could provide some quick training and information pertaining to time management skills. Specific tips on how to avoid procrastination and get an early start in the course could be included as well. It would be very beneficial if the distance faculty were in attendance at the orientation session so that students could make a connection at the onset with the faculty and establish communication early on prior to actually beginning the course.

The SEDL administrators should carefully examine the printed information pertaining to distance courses and ensure that accurate descriptions of course format and expectations are clear. Review of such materials is essential in providing potential students the most clear and realistic picture of what is involved in taking a distance course. In addition to reviewing printed documents, administrators should provide accurate information to the academic advisors and other University personnel directly associated with recruitment and advising of students. Perhaps, the easiest way to ensure the dissemination of information is accurate in academic advising and recruitment is to hold a meeting to discuss details of the program and 
specific course formats or provide a written document to those individuals involved. Periodic meetings or dissemination of documents should also be conducted to provide updates of information that may change throughout the year.

SEDL administrators should perform continual evaluation to analyze feedback concerning student satisfaction with the distance courses. The regular evaluation of student satisfaction allows the administrator to coordinate efforts to reduce attrition and report the effects of the interventions implemented to reduce student attrition.

\section{Recommendations for Further Study}

This study examined undergraduate student perceptions of faculty-student communication, student time management, student expectations and quality of instruction as related to student success. The purpose of this study was to identify the predictors of student success in distance education courses.

Future research should focus on the level of student success in order to compare the students representing each grade earned in the course as related to each independent variable. This study experienced a very low return rate for unsuccessful students; therefore such comparisons were not feasible. Institutions could specifically target unsuccessful individuals by incorporating a follow-up telephone call if a survey response is not received from an unsuccessful student. The use of a follow-up telephone call to gather survey data would require tracking of students who returned surveys and students who did not respond to the survey. The telephone call compromises the anonymity of the participant, but the insight provided by such a tool would prove to be beneficial to the institution. The institution would be 
able to identify the strengths and challenges of the unsuccessful students in order to determine what methods of intervention may be implemented to decrease attrition.

It is important for colleges and universities to recognize what goes on in their own distance education courses and programs. However, it would be interesting to compare student perception's of faculty-student communication, student time management, student expectations, and quality of instruction as related to level of student success at other institutions. A recommendation for future research is to examine more than one institution. This study was limited in that it was conducted at one institution. Therefore, the findings of this study are generalized back to the population sampled at Mountain State University. Future research would prove beneficial and increase generalizability if the research was conducted at similar institutions with similar distance education modalities. Such a study would provide comparison of groups across institutions as well as provide information for each institution in the study. 


\section{REFERENCES}

Abernathy, D. J. (1998). The WWW of distance learning: Who does what and where? Training \& Development, 52(9), 29-31.

Alexander, P. (1999). Pros and cons of cyberclassrooms. Marketing News, 33(16), 10.

Anderson, T. D. \& Garrison, D. R. (1995). Transactional issues in distance education: The impact of design in audio teleconferencing. The American Journal of Distance Education, 9, 27-45.

Arbaugh, J. B. (2000). Virtual classroom characteristics and student satisfaction with internet-based MBA courses. Journal of Management Education, 24(1), $32-54$.

Babbie, E. (1990). Survey Research ( $2^{\text {nd }}$ ed.). Belmont: Wadsworth Publishing Company.

Ballon, M. (1999). Bringing college home by TV and Internet. Inc., 21, 19-20.

Bartels, J. \& Willen, B. (1985, August). Problems of comparing drop-out in different distance education systems. Paper presented at the Thirteenth World Conference of the International Council of Distance Education, Melbourne, Australia.

Bean, J. P. (1982, March). The interaction effects of GPA on other determinants of student attrition in a homogenous population. Paper presented at the Annual Meeting of the American Educational Research Association, New York. 
Bink, M. L., Biner, P. M., Huffman, M. L., Greer, B. L. \& Dean, R. S. (1995).

Attitudinal college/course-related, and demographic predictors of performance in televised continuing education courses. The Journal of Continuing Higher Education, 43(2), 14-20.

Brawer, F. B. (1996). Retention-attrition in the nineties (EDO-JC-96-06).

Washington, D. C.: Office of Educational Research and Improvement. (ERIC Document Reproduction Service No. ED393510).

Campbell, D. T. \& Stanley, J. C. (1963). Experimental and quasi-experimental designs for research. Chicago: Rand McNally.

Carr, S. (2000, February 11). As distance education comes of age, the challenge is keeping the students. Chronicle of Higher Education, 46(23), A39-A42.

Chyung, Y., Winiecki, D. J. \& Fenner, J. A. (1998). A case study: Increase enrollment by reducing dropout rates in adult distance education. Proceedings of the Annual Conference on Distance Teaching \& Learning, Madison, WI, 97-102. (ERIC Document Reproduction Service no. ED422848).

Cooper, L. (2000). Online courses. Distance Education, 27(6), 86-92.

Curran, C. (1997). ODL and traditional universities: Dichotomy or convergence? European Journal of Education, 32(4), 335-346.

Dille, B. \& Mezack, M. (1991). Identifying predictors of high risk among community college telecourses students. The American Journal of Distance Education, 5(1), 24-35.

Dixon, P. (1997). Is virtual college right for you? The Futurist, 31(4), 48-49. 
Eastmond, D. V. (1998). Adult learners and Internet-based distance education. New Directions for Adult and Continuing Education, (78), 33-41.

Evans, A. (1986). Media managers and distance education. Media Management Journal, 5, 22-23.

Ekins, J. M. (1992, September). The development of study processes in distance learning students. Paper presented at a meeting of the Asian Association of Open Universities, Korea.

Fjortoft, N. F. (1995, October). Predicting persistence in distance learning programs. Paper presented at the meeting of the Mid-Western Educational Research Meeting, Chicago.

Fowler, Jr., F. J. (2002). Survey research methods ( $3^{\text {rd }}$ ed.). Newburg Park: Sage Publications, Inc.

Frew, E. \& Weber, K. (1995) Towards a higher retention rate among distance learners. Open Learning, 10(2), 58-61.

Garland, M. R. (1993a). Ethnography penetrates the "I didn't have time" rationale to elucidate higher order reasons for distance education withdrawal. Distance Education, 5(1-2), 6-10.

Garland, M. R. (1993b). Student perceptions of the situational, institutional, dispositional and epistemological barriers to persistence. Distance Education, 14(2), 181-198.

Gibson, C. \& Gibson, T. (1995). Lessons learned from 100+ years of distance learning. Adult Learning 7(1), 15. 
Guernsey, L. (1998). Mulling the surprising popularity of distance education for the not-so-distance. Chronicle of Higher Education, 44(29), A29-A30.

Gulick, L. \& Urwick, L. (1969). Papers on the science of administration. New York: Institute of Public Administration.

Hall, J. (1995). The convergence of means. Educom Review, 30(4), 42-45.

Hall, J. W. (1990). Distance education: Reaching out to millions. Change, 22(4), 48.

Hankin, J. N. (1999). Alice, the college teacher, and the rottwelier in wonderland:

The prospects and problems of distance education. Executive Speeches, 14(2), 18-21.

Herrmann, A. (1988). A conceptual framework for understanding the transitions in perceptions of external students. Distance Education, 9(1), 5-26.

Hillman, D. C., Willis, D. J. \& Gunawardena, C. N. (1994). Learner-interface interaction in distance education: An extension of contemporary models and strategies for practitioners. The American Journal of Distance Education, 8(2), $30-42$.

Hogan, R. (1997, July). Analysis of student success in distance learning courses compared to traditional courses. Paper presented at the Annual Conference on Multimedia in Education and Industry, Chattanooga, TN.

Holmberg, B. (1989). The concept, basic character and development potentials of distance education. Distance Education, 10(1), 127-135.

Inman, E. \& Kerwin, M. (1999). Instructor and student attitudes toward distance education. Community College Journal of Research \& Practice, 23(6), 581592. 
Janssen, T. \& Carton, J. S. (1999). The effects of locus of control and task difficulty on procrastination. Journal of Genetic Psychology, 160(4), 436-443.

Jegede, O., Taplin, M., Fan, Y. K., Chan, M. K. \& Yum, J. (1999). Difference between low and high achieving distance learners in locus of control and metacognition. Distance Education, 20(2), 255-273.

Jerome, M. (1999). Colleges 'go the distance' for student's learning. Westchester County Business Journal, 38(47), 18-20.

Johnson, B. \& Christensen, L. (2000). Educational Research: Quantitative and qualitative approaches. Boston: Allyn and Bacon.

Kember, D. (1989). A longitudinal-process model of drop-out from distance education. Journal of Higher Education, 60(3), 278-301.

Kerka, S. (1988). Strategies for retaining adult students: The educationally disadvantaged. Office of Educational Research and Improvement (ED), Washington, DC. ERIC ED 299455.

Kerlinger, F. N. (1986). Foundations of behavioral research. New York: Holt, Rinehart and Winston.

Kirtley, K. E. (2002). A study of student characteristics and their effect on student satisfaction with online courses. Unpublished doctoral dissertation, West Virginia University, Morgantown, WV.

Klesius, J., Homan, S. \& Thompson, T. (1997). Distance education compared to traditional instruction: The students' view. International Journal of Instructional Media, 24(3), 207-220. 
Leasure, A. R., Davis, L. \& Thievon, S. L. (2000). Comparisons of student outcomes and preferences in a traditional vs. World Wide Web based baccalaureate nursing research course. Journal of Nursing Education, 39(4), 149-154.

Lewis, L. Farris, E. \& Alexander, D. (1997). Distance education in higher education (Report \#NCES-08-062). Washington, D. C.: National Center for Educational Statistics (ERIC Document Reproduction Service No. ED431829).

Losty, B. P. \& Broderson, D. D. (1980). Who succeeds? A comparison of transcriptions of graduates and inactive students of a nontraditional bachelor of arts program. Alternative Higher Education: The Journal of Nontraditional Studies, 25, 91-99.

Matthews, D. (1999). The origins of distance education and its use in the United States. THE Journal, 27(2), 54-61.

Minich, E. L. (1996, January). Using student feedback to improve distance education. Unpublished manuscript, Florida Community College at Jacksonville.

Morgan, C. K. \& Tam, M. (1999). Unraveling the complexities of distance education student attrition. Distance Education, 20(1), 96-108.

Morris, B. A. (1999). Distance learning. Rough Notes, 142, 32-34.

Nesler, M. S. (1999, November). Factors associated with retention in a distancebased liberal arts program. Paper presented at the North East Association for Institutional Research Conference, Newport, RI.

Neumann, P. (1998). Risks of e-education. Communications of the ACM, 41(10), 136. 
Omoregie, M. (1997, April). Distance learning: An effective educational delivery system. (ERIC Document Reproduction Service No. ED418683).

Ozga, J. \& Sukhnandan, L. (1998). Undergraduate non-completion: Developing an exploratory model. Higher Education Quarterly, 52(3), 316-333.

Palloff, R. M. \& Pratt, K. (1999). Building learning communities in cyberspace: Effective strategies for the online classroom (pp. 73-86). Jossey-Bass Publishers, Inc.

Parker, A. (1999). A study of variables that predict dropout from distance education. International Journal of Educational Technology, 1(2), 1-10.

Peek, R. (2000). A distance learning reality check. Information Today, 17(2), 30.

Phillips, V. (1998). Virtual classrooms, real education. National's Business, 85(5). $41-44$.

Prather, J. E. \& Hand, C. A. (1986, October). Retention of non-traditional students. Paper presented at the Annual Meeting of the Southern Association for Institutional Research, Pipestem, WV.

Pugliese, R. R. (1994). Telecourse persistence and psychological variables. The American Journal of Distance Education, 8(3), 22-39.

Roberts, D. (1984). Ways and means of reducing early student drop-out rates. Distance Education, 5(1), 50-71.

Roweton, W. E. \& Bare, C. (1991). Predicting rural college retention. Nebraska, Chadron State College, Department of Psychology \& Department of Mathematics (ERIC Document Reproduction Service No. ED335185). 
Saba, F. (2000). Illuminating practice: Two recent outstanding studies. Distance Education Report, 2(10), 3.

Smith, G. M. (1998). Education poised to go the 'distance'. National Underwriter, 102(45), 19-20.

Snell, J. \& Mekies, D. (1999). Online education and academic rigor: A research note. Journal of Instructional Psychology, 23(3), 194-195.

Spanier, G. B. (2000). Five challenges facing American higher education. Executive Speeches, 14(6), 19-24.

Stephenson, S. (1997). Distance mentoring. Journal of Educational Technology Systems, 26(2), 181-186.

Stone, T. E. (1992). A new look at the role of locus of control in completion rates in distance education. Research in Distance Education, 4(2), 6-9.

Taplin, M. \& Jegede, O. (2001). Gender differences in factors influencing achievement of distance education students. Open Learning, 16(2), 133-154.

Terenzini, P. T. \& Pascarella, E. T. (1980). Toward the validation of Tinto's model of college attrition: A review of recent studies. Research in Higher Education, $12,271-282$.

Towles, D. E., Ellis, J. R. \& Spencer, J. (1993, May). Student persistence in a distance education program: The effect of faculty-initiated contact. Paper presented at the Annual Forum of the Association for Institutional Research, Chicago, IL.

Tweney, D. (1999). Distance learning is no real substituted for real-world education. Infoworld, 21(20), 66. 
Tysome, T. (January 5, 2001). Distance learning fails students. The Times Higher, 7 and page 12 .

Wade, W. (1999). What do students know and how do we know that they know it? THE Journal, 27(3), 94-99.

Wang, A. Y. \& Newlin, M. H. (2000). Characteristics of students who enroll and succeed in psychology web-based classes. Journal of Educational Psychology, 92(1), 137-143.

Weber, J. (1999). School is never out. Business Week, 3649, 164-168.

Weidman, J. C. (1985, August). Retention of nontraditional students in postsecondary education. Paper presented at the Annual Meeting of the American Educational Research Association, Chicago, IL.

White, C. (1999). Expectations and emergent beliefs of self-instructed language learners. System, 27(4), 443-457.

White, H. S. (1999). The changes in off-campus education. Library Journal, 124(3), 128-130.

Wilkes, W. C. \& Burnham, B. R. (1991). Adult learner motivations and electronic distance education. The American Journal of Distance Education, 5(1), 43-50.

Wilkinson, T. W. \& Sherman, T. M. (1989). Distance education and student procrastination. Educational Technology, 29(12), 24-27.

Wilkinson, T. W. \& Sherman, T. M. (1990). Perceptions and actions of distance educators on academic procrastination. The American Journal of Distance Education, 4(3), 47-56. 
York, C. Bollar, S. \& Schoob, C. (1993). Causes of college retention: A systems prospective. Paper presented at the American Psychological Meeting, Toronto.

Zajkowski, M. (1997). Price and persistence in distance education. Open Learning, $12(1), 12-23$. 


\section{APPENDIX A}

Distance Education Student Satisfaction Survey 


\section{Distance Education Satisfaction Survey}

Read each item carefully and circle the appropriate response. Use your most recent distance education course experience to complete the survey.

1. During the course, I attempted to contact my instructor:

0 times $\quad 1-5$ times $\quad 6-10$ times 11 or more times

2. My instructor responded to my phone calls or emails:

within 24 hours within 2-3 days within 4-7 days within 8 days or more

3. My instructor was available during the times listed on the syllabus: always often rarely never

4. The turnaround time for grades on assignments and exams was: excellent good fair poor

5. My time management skills in this course were:

excellent good fair poor

6. I found the challenge of balancing an education, family and/or career: easy challenging difficult impossible

7. My ability to pace myself in the course was: excellent good fair poor

8. Once I registered for the course, I began working on assignments or exams within 1-4 weeks 2-3 months $4-5$ months 6 months

9. I found the amount of content, assignments and exams in the course was: greater than I expected about what I expected less than I expected

10. The self-directed nature of this course was: greater than I expected about what I expected less than I expected

11. My ability to learn and understand the content was: greater than I expected about what I expected less than I expected

12. The quality of my work submitted for grading was: greater than I expected about what I expected less than I expected

13. Once I registered for the course, I received the syllabus and all course materials in:
$1-2$ weeks
3-4 weeks
5-6 weeks
7-8 weeks

14. Compared to a traditional course, I found the quality of my Independent Study course to be excellent good fair poor

15. The content of the course was:

very easy difficult easy very difficult

16. The support and guidance provided by my instructor was: excellent good fair poor

17. The grade I earned in this course was $a(n)$ :
A
B
C
D
F $\quad$ W (withdrew)

Sex: male female

age

Please return the completed survey in the envelope provided. If the envelope has been misplaced return to Rhonda Shepperd, Mountain State University, PO Box 9003, Beckley, WV 25802. 


\section{APPENDIX B}

Mountain State University and West Virginia University Institutional Review Boards for the Protection of Human Subjects Approval 


\section{Mountain State University"}

INSTITUTIONAL REVIEW BOARD

\section{Memorandum for Record}

To: Dr. Eagle

CC: Ms. Shepperd

From: Dr. R. A. L'heureux

Date: $7 / 16 / 2002$

Re: IRB Action Number: 2002-007. Dissertation: Predictors of Student Success in Distance Education

Researcher: Ms. Rhonda Shepperd

In accordance with the requirements specified on page 7 of Mountain State University's Manual of Policies and Procedures Governing Research, the Institutional Review Board (IRB) of Mountain State University has reviewed the research proposal of Rhonda Shepperd (Doctoral Candidate - Marshall University Educational Leadership Studies). Specific areas of review were:

- Nature of the research: Sensitivity of the issue and the importance of exercising care in handling any information received from these participants on this subject

- Extent of subject involvement

- Privacy protection procedures

- Data safeguard procedures

- Maintenance of data after research is complete 
Conclusions of Review:

- Ms. Shepperd's research meets the criteria to be classified as "Exempt" from further IRB review, i.e., research requires minimal human subject participation and the risk of harm to the participants is nearly zero. Ms. Shepperd's research design maintains participant's anonymity and is seeking perceptual data. As indicated in MSU's IFB Policies and Procedures Manual, exempted research does not require further oversight by the institutional review board.

- Research is recommended for approval.

Richrard A. L'Heureux, Pn.D., CPCM'

Chair, Mountain State University IRB 


\section{West VirginiaUniversity}

College of Human Resources and Education

August 20, 2002

MEMORANDUM

TO: $\quad$ Rhonda Shepperd

FROM: $\quad$ Anne H. Nardi

Interim Dean

RE: $\quad$ Human Resources \& Education H.S. \#2002-078

Title: "Predictors of Student Success in Distance Education"

Your Application for Exemption for the above-captioned research project has been reviewed under the Human Subjects Policies and has been approved. Attached is the original of your cover letter with the signed stamp of approval. This must accompany your survey or questionnaire.

This exemption will remain in effect on the condition that the research is carried out exactly as described in the application.

Best wishes for the success of your research.

cc: Deans Office

Student Advising and Records

Teresa Eagle, Advisor 


\section{APPENDIX C}

Cover Letter 


\section{WestVirginiaUniversity}

College of Human Resources and Education
APPROVED BY THE COLLEGE OF HUMAN RESOURCES \& EDUCATION

DATE:

August 22, 2002

Dear Student:

The School of Extended and Distance Learning records at Mountain State University indicate that you were enrolled in an Independent Study course during the Summer I, Summer II or Fall 2001 terms. You have been selected based on these records to participate in a research study of distance education students. The purpose of this study is to learn more about student satisfaction in Independent Study courses. Your response will help the University gain insight into the Independent Study Courses.

Your participation in this study is strictly voluntary. Your responses are completely anonymous and you will not be identified on an individual basis in this study or any reports following thereafter. This research project was reviewed and approved by the Institutional Review Boards for the Protection of Human Subjects at Mountain State and West Virginia Universities.

I know that you are very busy and that your time is valuable. The enclosed survey instrument will only take approximately five minutes to complete. The Distance

Education Satisfaction Survey will ask a few questions about your level of satisfaction with faculty-student communications, time management, expectations and quality of instruction while enrolled in the Independent Study course. Your participation is strictly voluntary and you do not have to respond to every item.

I am conducting this survey for my dissertation for the Doctoral program in Higher Education Administration at West Virginia University. I would be most grateful for your help in completing this survey.

Please complete and return the survey in the enclosed prepaid reply envelope by September 3, 2002. Your help is appreciated!

Respectfully yours,

Rhonda S. Shepperd

Doctoral Candidate

West Virginia University

Enclosure 


\section{APPENDIX D}

Follow-Up Letter 
September 9, 2002

Dear Student:

Recently, you received a letter and survey instrument requesting your help with a research project investigating student satisfaction of Independent Study courses at Mountain State University. If you have already completed and returned the survey, your participation and help in the research project has been most appreciated and I am truly grateful for your efforts. If you have not yet completed the survey, please consider this a second request for your help. I have enclosed an additional survey and return envelope for you.

Your participation in this study is strictly voluntary. Your responses will remain anonymous and you will not be identified on an individual basis in this study or any reports following thereafter. This research project was reviewed and approved by the Institutional Review Boards for the Protection of Human Subjects at Mountain State and West Virginia Universities.

I know that you are very busy and that your time is valuable. The enclosed survey instrument will only take approximately five minutes to complete. The Distance Education Satisfaction Survey will ask a few questions about your level of satisfaction with faculty-student communication, time management, expectations and quality of instruction while enrolled in the Independent Study course. You may choose not to respond to any part of the study.

I am conducting this survey for my dissertation for the Doctoral program in Higher Education Administration at West Virginia University. I would be most grateful for your help in completing this survey.

Please complete and return the survey in the enclosed prepaid reply envelope by September 23, 2002. Your help is extremely appreciated!

Respectfully yours

Rhonda S. Shepperd

Doctoral Candidate

West Virginia University

Enclosure

Educational Leadership Studies • Educational Psychology • Social and Cultural Foundations • Technology Education

(Phone) 304 293-3049 व (FAX) 304 293-2279 a PO Box 6122. Allen Hall a Morgantown WV 26506-6122

Equal Opportunity / Affirmative Action Institution 